Georgia State University

ScholarWorks @ Georgia State University

\title{
Exploring the Role of Culture and Race in African American Adolescents
}

Obari Sipho Yohance Cartman

Follow this and additional works at: https://scholarworks.gsu.edu/psych_theses

Part of the Psychology Commons

\section{Recommended Citation}

Cartman, Obari Sipho Yohance, "Exploring the Role of Culture and Race in African American Adolescents." Thesis, Georgia State University, 2007. doi: https://doi.org/10.57709/1061213

This Thesis is brought to you for free and open access by the Department of Psychology at ScholarWorks @ Georgia State University. It has been accepted for inclusion in Psychology Theses by an authorized administrator of ScholarWorks@ Georgia State University. For more information, please contact scholarworks@gsu.edu. 


\title{
EXPLORING THE ROLE OF RACE CULTURE AND RACE IN AFRICAN AMERICN ADOLESCENTS
}

by

\section{OBARI CARTMAN}

Under the direction of Roderick J. Watts

\begin{abstract}
There are myriad definitions of the terms race, ethnicity and culture in social sciences literature. Often these terms are used interchangeably with no conceptual rationale. This study aims to contribute to our greater understanding of the similarities and differences between the conceptualization and use of race and culture as they are experienced by African American adolescents. Multiple regression analyses and factor analysis were conducted for 223 African American high school aged students who completed a survey about racial and ethnic identity and a variety of positive youth development outcomes. Results showed preliminary support for race and culture being distinguishable yet intricately related. Results are also presented that compares the relationship of either a racial or cultural orientation on various youth development outcomes.
\end{abstract}

INDEX WORDS: Race, Culture, Identity, Adolescents, African American, Ethnicity, African-centered 
EXPLORING THE ROLE OF CULURE AND RACE IN AFRICAN AMERICAN ADOLESCENTS

\author{
by \\ OBARI CARTMAN
}

A Thesis Submitted in Partial Fulfillment of the Requirements for the Degree of

\author{
Master of Arts \\ In the College of Arts and Sciences \\ Georgia State University
}


Copyright by

Obari Sipho Yohance Cartman

2007 
EXPLORING THE ROLE OF CULURE AND RACE IN AFRICAN AMERICAN ADOLESCENTS

by

OBARI CARTMAN

Major Professor: Roderick Watts

Committee: Leslie Jackson

Julia Perilla

Electronic Version Approved:

Office of Graduate Studies

College of Arts and Sciences

Georgia State University

August 2007 
TABLE OF CONTENTS

CHAPTER

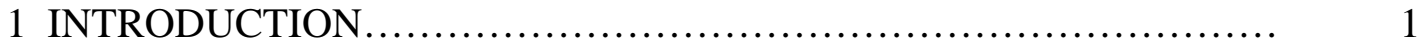

2 METHODS........................................................... 21

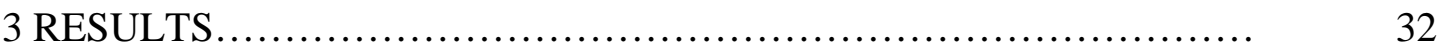

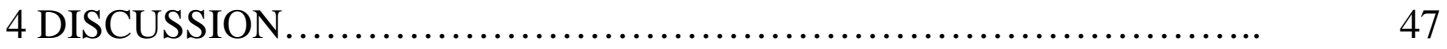

5 REFERENCES................................................... 5

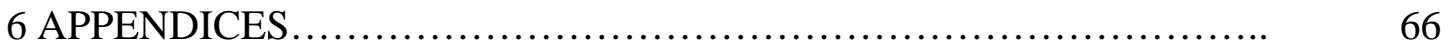




\section{LIST OF TABLES}

Table 1. Dependent Variables, the Measures Used to Assess Them and Their

Reliability Coefficients

Table 2. Item Loadings, Eigenvalues, and Reliabilities of Principal Components

Analysis

Table 3. Factors Organized by Orientation

Table 4. Zero-Order Intercorrelations for Cultural and Racial Orientation.

Table 5. Descriptive Statistics for Continuous Variables on Regression Models...

37

Table 6.1. Hierarchical Regression Analysis for Cultural and Racial Orientation

Predicting Academic Success

Table 6.2. Hierarchical Regression Analysis for Cultural and Racial Orientation

Predicting Well Being.

Table 6.3. Hierarchical Regression Analysis for Cultural and Racial Orientation

Predicting Social Skills....

Table 6.4. Hierarchical Regression Analysis for Cultural and Racial Orientation

Predicting Social Political Efficacy. ...

Table 6.5. Hierarchical Regression Analysis for Cultural and Racial Orientation

Predicting Community and Political Involvement

Table 7. Summary of Differential Contribution of Cultural and Racial 
Culture and race are complex phenomena for the people of African ancestry, particularly in the United States. Among African Americans there exists a myriad of perspectives regarding what constitutes their culture of origin. Similarly, concepts concerning race for African Americans are embedded within complicated social, biological, political and historical factors. Nonetheless, despite its shortcomings, psychological theory and research on African American as a racial group is much more advanced than the research on African American culture. Much more research is needed to further psychology’s knowledge of culture's role in the experiences of contemporary African Americans. There are distinct elements of a culture that developed from African Americans' history and experiences after the capture and enslavement of Africans from 1619-1865. The remnants of traditional African cultural values and philosophies that have survived the atrocities endured in the Americas continue to influence the way African Americans see the world. There are a variety of theoretical models aimed at understanding African Americans’ individual and group experiences; this review will highlight some of the leading perspectives on African American self-concept, identity, worldview, and socialization in relation to culture, ethnicity and race. The research questions for this study will compare the roles of culture and race in the psychosocial development of African Americans, specifically during adolescence.

\section{Definitions of Race, Culture and Ethnicity}

The psychological literature is fraught with vague and/or conflicting conceptualizations of what culture is, and the terms race, ethnicity, and culture are often 
used interchangeably. For instance, Phinney (September, 1996) advocated the combining of ethnicity and race into a single construct in psychology 'because of the wide disagreement on its [race’s] meaning and usage for psychology' (as cited in Helms, 1997, p.918). Similarly, culture is difficult to define for African Americans because ef uncertainties about the historical point of reference for “African culture.” Conceptualizations of culture based on traditional (pre-colonial) African cultures or classical African civilization can be very different from a conceptualization that emphasizes the African experience in America. In the case of race, the discrepancies among definitions are most problematic when comparing research findings across studies. Race has been described as referring to a group of people who share biological and phenotypic characteristics that signify group membership but also the social meaning of such membership in the larger society (Jones, 1997). More recently, it has been argued that race is a social construction typically used to create and justify social and political hierarchies that maintain status quo for the dominant race (Smedly and Smedly, 2005; Helms, 1994). Ethnicity refers to an embodiment of values, institutions, and patterns of behavior which incorporate a group’s historical experience and worldview (Deng, 1997, as cited in Chang and Dodd, 2001). As for culture, there are many definitions but no consensus (APA Multicultural Guidelines, 2002). For this study, culture includes two separate components; the first is material, which refers to objects such as clothes, buildings, tools, etc. The second is psychological and sociological-it includes elements such as social norms, roles, beliefs, and values, and these are the aspects of culture that are of most interest to this study. "These social and subjective cultural elements include a wide range of topics, such as familial roles, communications patterns, affective styles, 
and values regarding personal control, individualism, collectivism, spirituality, and religiosity” (Betancourt \& Lopez, 1993). There is considerable conceptual overlap between the terms culture and ethnicity; however the key distinction is that ethnicity focuses on the interplay among groups in a larger shared, cultural environment. The key distinctions made for this study, however, are those between culture and race.

\section{Distinctions between race and culture}

There are a number of ways to sharpen the distinction between culture and race. Some studies have highlighted the distinction between racial and cultural dimensions of identity and worldview. Brookins‘ (1994) analysis of the relationship between Africancentered values and racial identity attitudes suggests that these two constructs are different domains of psychological health for African Americans; the cultural domain is "reflective of a basic humanistic value system" and the racial domain is "related to how one intends to cope with current sociopolitical realities” (p.141). Other researchers have made distinctions based on perceptions of the self. Allen and Bagozzi (2001) compared and contrasted the influence of African-centered self-concepts (African selfconsciousness) and those that were more politically and socially oriented (Black identity). They found no relationship between African self-consciousness and Black identity, and these two constructs were related differentially to a variety of outcomes including social and political orientations. For example, stronger African self-consciousness was associated with elements in the African American community that support substantial social and political reform, while Black identity had no relationship to social or political concerns. 
Although some theorists have explored the social and psychological distinctions between a race and culture, most of the literature examines the constructs independently. For that reason, the review that follows will examine these and related constructs separately followed by a summation of the major themes.

Racial Perspectives in Psychological Literature: Theory, Research and Measurement

Psychologists have shown considerable interest in investigating African Americans’ experience of race, racial identification, interracial relations, ethnicity, and a variety of related phenomena. It has long been recognized that race-related intergroup dynamics have implications that span the legal, political, economic, social and psychological lives of African Americans and race has simultaneously been associated with oppression and pride, alienation and accomplishment (Jones, 1997). To complicate matters, while a person can be classified as a member of a certain race because of his/her physical characteristics, there is variability regarding an individual's level of identification with his/her race. It often depends on context, but for some African Americans race is less salient an aspect of their identity as is gender, sexual orientation, socioeconomic status, or other elements of identity.

There is a considerable body of theoretical and empirical literature on African American racial identity. One of the earliest and most prominent models of racial identity development is Cross’ theory of “Negro to Black conversion” (Cross, 1971). Cross introduced his theory to describe the process through which Blacks reconstruct their sense of identity that was damaged as a result of oppression. His theory of Nigrescence (which means “to become Black”) is described as movement through five 
distinct stages of development, beginning with an individual having a primarily

Eurocentric frame of reference where Blackness is devalued, to achieving a sense of inner security with Blackness (Parham, White, and Ajamu, 1999).

Similarly much of the contemporary literature describes racial identity as a multidimensional construct (e.g., Cokley, Helm, 2001; Walsh, 2001; Sanders-Thompson, 2001; Sellers, et al., 1998). Sellers’ Multidimensional Model of Racial Identity, for instance, suggests four distinct, but interrelated dimensions of racial identity: 1) racial salience, 2) the centrality of the identity, 3) the regard with which the person holds the group associated with the identity, and 4) the ideology associated with the identity. The ideology dimension is further broken down into four dynamic, overlapping categories: (1) a nationalist philosophy; (2) an oppressed minority philosophy; (3) an assimilation philosophy; and (4) a humanist philosophy. The nationalist philosophy emphasizes the political and economic self-reliance of African Americans, while the oppressed minority ideology recognizes more of the common experiences between African Americans and other groups that have and continue to be oppressed. The assimilation philosophy encourages African Americans to work within the parameters of mainstream American systems for success, and a humanist philosophy suggests that all people share an important kinship and the focus should be on the common experiences of a human family, regardless of race, gender, class or any other superficial categories. This theory has received moderate to good empirical support via the instrument developed to assess it, the Multidimensional Inventory of Black Identity (Sellers, Shelton, Cooke, Chavous, Rowley, and Smith, 1998; Cokley \& Helms, 2001; Walsh, 2001). 
The Multidimensional Inventory of Black Identity (MIBI) is a 65-item inventory that was created to assess centrality, regard and ideology in African Americans (Sellers, Johnson, Chavous, Shelton \& Smith, 1997). As a result, among 306 college students, conceptually relevant behavioral outcomes were found to be associated with MIBI subscales in a predictable fashion. For instance, increased contact with African Americans was related to greater nationalist attitudes, higher tendency to define one's self with respect to race, and increased positive regard for African Americans, while increased contact with Whites was associated with assimilation and humanist ideologies (Sellers, Shelton, Cooke, Chavous, Rowley, \& Smith, 1998). Cokley and Helm (2001) used confirmatory factor analysis to test the theory that the MIBI is based on and found partial support for the MIBI as a reliable and valid measure of African American identity, suggesting reconsiderations at the theoretical level of the definitions of certain constructs. Sellers et al. (1998) posit that the study of racial identity of African Americans, in general, has been provocative and insightful, but too often racial identity has been understood as a response to centuries of oppression and stigmatization, and "it might also include the prosocial operations that cultural affiliations provide individuals” (p.275).

Sanders-Thompson's (2001) study of 426 adults in St. Louis suggests four alternative dimensions. First is a physical identity dimension which refers to a sense of acceptance and comfort with the physical attributes of African Americans. A psychological identity refers to the individual's sense of commitment and pride, while a sociopolitical identity considers social and political issues facing the black community. Finally, a cultural racial identity refers to an individual's knowledge of and commitment to the cultural traditions of African Americans (Sanders-Thompson, 2001). 
In sum, the racial identity literature has laid a strong empirical foundation for the study of African American's internalization of and resistance to white supremacy and racial attitudes and behaviors amidst a complex social, political and historical backdrop. A consistent theme throughout this literature is that racial identity development is complex, and important to understand for African Americans because of its potential to foster positive attitudes about self and reject notions of white supremacy. Whether looking at developmental stages or more stable perspectives, racial identity is best explained using multiple dimensions. Some of the dimensions included in previous literature include explicit cultural elements, and some do not. However, the present study attempts to add clarity the degree to which cultural orientation is related to, or distinct from racial orientation, and to what extent culturally oriented dimensions play a role in developmental outcomes.

Stevenson's theory of racial socialization represents something of a hybrid of cultural and racial ideas. (Stevenson, 1995). According to Stevenson, “ Racial socialization represents a set of communications, interactions, and behaviors between parents and youth regarding how African Americans ought to decide about their cultural heritage as well as how to respond to the racial hostility, empowerment, or confusion of American society (Stevenson et al., 2002, p.85). Stevenson's (1994) work led to the development of a multidimensional Scale of Racial Socialization for African American adolescents that will be discussed later in further detail. Stevenson (1998) later advanced his own conceptualization of racial socialization. He moves beyond the traditional oppression and resistance-centered approach where the developmental process is a function of racist and discriminatory experiences, the respondent's perceptions of Whites, 
or as an acceptance of pro-African American cultural styles and affiliation. Instead, he suggests that an accurate assessment of racial socialization must include measuring family and environmental interactions and other system-level contextual elements (Stevenson, 1998).

As racial identity and socialization theory incorporates more considerations of culture and values, the boundaries between the racial, ethnic, and cultural distinction become less clear. In a review of research on ethnic identity in adolescents and adults, Phinney (1990) noted that considerable overlap exists among conceptual frameworks for ethnicity, culture, identity, etc. She further notes the imbalance of theoretical writings over empirical research regarding ethnic identity, particularly in adolescents, and she notes that the greatest need in ethnic identity research is to devise reliable and valid measures of ethnic identity (Phinney, 1990).

African Centered Cultural Perspectives in Psychology: Theory, Research and Measurement

Although there have been some gains in the last ten years, “The study of culture has largely been ignored in mainstream psychology... [and] has focused on the comparative (cross-cultural) study of behavioral phenomenal, without much regard for the measurement of cultural variables and their implications for theory” (Betancourt and Lopez, 1993, p. 632). However, this is not to say that work on cultural psychology is not being done. Their work has garnered limited attention in the mainstream, but a number of psychologists of African descent have been developing theory and, to some extent, research grounded in traditional African-centered principles and philosophies (e.g., 
Akbar, 1995; Nobles, 1986; Azibo, 1996; Kambon, 1992; Hilliard, 1997; Myers, 1988;

Baldwin and Bell, 1985). Afrocentricity was defined by Asante (1980) as a worldview and analysis centered in traditional African values and philosophies. His ideas are predated by Black nationalist ideas such as those by Karenga (1968) and others. Nobles (1998) adds, “African-centeredness...represents the intellectual and philosophical foundations upon which people of African ancestry should create their own scientific and moral criteria for authenticating the reality of human processes” (p.190) For these theorists, African-centeredness represents a core and fundamental quality of being.

The discussion of "traditional” African culture is based on the values, practices and worldview that existed before the widespread influence of colonialism and cultural imperialism by European and Arab Muslim populations. This analysis draws from the Pan-African perspective of scholars and activists such as Marcus Garvey, WEB Dubois and John Henrik Clarke who emphasize the commonalities among cultures across the continent of Africa.

African-centered researchers have begun to develop instruments that assess an African centered orientation at the broadest level. One of the earliest of such measures was Baldwin and Bell's (1985) African Self-Consciousness Scale (ASC) which was described as an African- centered personality questionnaire. This 42-item measure is based on the following four dimensions: (1) recognition of one’s African identity and heritage; (2) ideological and activity priorities placed on Black survival and liberation; (3) specific activity priorities placed on self-knowledge and self-affirmation (i.e. African centered values and customs); and (4) a position of resistance toward “anti-Black” forces. 
Additionally, core components of the framework underlying this instrument is the communal nature "which characterizes the self-extension orientation of African people“ (Baldwin and Bell, 1985, p.62). An assessment of the reliability, factor structure, and validity of the ASC by Stokes et al. (1994) suggests that the dimensions originally proposed by Baldwin and Bell (1985) are consistent with this study’s factor analysis, and, overall, the results provided good support for the viability of the ASC for researching African American self-concept.

Another Africentrism Scale was developed by Grills and Logshore (1996) to assess fundamental elements of an African centered worldview (i.e. spirituality, collective and holistic orientation, nonmaterialism, harmony with nature). Specifically, the Africentrism Scale is based on the principles of the Nguzo Saba (also used as the seven principles of Kwanzaa). The principles are unity, self-determination, collective work and responsibility, cooperative economics, creativity, purpose, and faith. In a cross-validation of the Africentrism Scale, Kwate (2003) found that the older and more educated individuals in his sample endorsed more Africentrism.

\section{Recurring themes in African Centered Psychology}

A number of researchers have examined specific dimensions of an African centered orientation. The themes in this literature are at least as consistent as those in the racial identity literature. They include harmony with nature, survival of the group/group synthesis, cooperation/collective responsibility, complementarity/ commonality, circularity/reciprocity, and spirituality (Kambon, 1996). Many African centered psychologists urge their colleagues to "forego the tendency to characterize cultures by 
general orientations (e.g., individualism vs. collectivism) and move toward representations that are more faithful to the complexities, dynamics, and dialectical nature of culture” (McLoyd, 2004, p.185). The two most prominent concepts that are consistently included as fundamental to an African centered worldview are spirituality and an extended sense of self.

\section{Spirituality}

Ani (1980) suggests that an understanding of the essentially spiritual nature of human existence is the most common feature of African people’s worldview. Spiritual power has enabled African people's survival through such tragedies as the American institution of slavery. In an article discussing authentic African identity, Nobles (1998) described human reality as it is understood in several different African cultural traditions. The Bantu-Kongo people in Central Africa believe that the person is both the container and instrument of Divine energy. Ancient Kemetic (Egyptian) philosophy purported that human beings are destined to live forever because the person is a manifestation or expression of $\mathrm{Nu}$, the primordial substance. The Zulu of South Africa believed that all phenomenon had their origins in a living consciousness they called “UQOBU”. According to the Akan of West Africa, the person is made up of two principal components, the immaterial/spiritual (Okra and Sunsum) and the material/physical (Honam), and the relationship between the soul and the body is so close that its union is indissoluble. Similarly the Mende believe the person is comprised of the Ngafa (the spirit) which is provided by the mother and the Nduwai (the flesh) that comes from the father; the Yoruba speak of the Ara (body) that can be touched, felt, damaged and 
disintegrates after death and the Emi (spirit) the divine element that links the person directly to God. There are numerous other examples of the prominence of spirituality for diasporic Africans (Nobles, 1998). Consequently, Nobles (1998) posits:

"Given this sense of human beingness, the observation regarding the spirituality of African people is somewhat of a misnomer. Spirituality pertains to having the quality of being spiritual. African people have more than the quality of being spiritual. In fact, for the African to be human is to be a spirit. Spirit is the energy, force or power that is both the inner essence and the outer envelope of human beingness” (p.193).

The African self

The African worldview incorporates a sense of self that incorporates family, community, ancestors, children yet to be born, and divine spiritual entities (Azibo, 1996). Moreover, “the African sees a continuity and harmony between nature and himself” (Akbar, 1996). Param, White, and Ajamu (1999) insist that the unit of analysis from this perspective is not the individual; instead fundamental human operations function to ensure the survival of the group (e.g. tribe, family, community). This perspective emphasizes interdependence, rather than independence, and interrelatedness, rather than separateness and it is captured in the West African saying "I am because we are and because we are therefore I am.” Therefore, people within a family or community are accountable for one another and individuals share in group accomplishments and failures. Boykin, Jagers, Ellison and Albury (1997) created a measure of this African-centered notion of communalism based on five core components: (1) primacy of social existence, (2) 
sanctity of social bonds and relations, (3) transcendence of group duties and responsibilities over individual concerns, (4) anchoring of individual identity in the group, and (5) an emphasis on sharing and contributing in support of the group. During the development of this scale Boykin et al. (1997) found good internal homogeneity and consistency across administrations of the Communalism Scale as indicated by measures of reliability, and the scale was also shown to have good convergent and divergent validity when compared to the established Scales of Social Interdependence.

\section{Integration of African and African-American cultural themes}

Several prominent theorists are pushing the boundaries of racial/ethnic research and theory by challenging some its previous assumptions. Myers and Haggins (1998) posit moving towards a theory of identity development grounded in an African American cultural reality with Africa as the origin of human culture and civilization. Many contemporary theories of Black identity, socialization and worldview incorporate elements of both African and African American culture. For example, Jones (1997) has proposed a model of African American ethos that incorporates distinct cultural elements; he calls it the TRIOS model, which stands for five essential factors that distinguish Black culture: Time, Rhythm, Improvisation, Oral expression and Spirituality. Time refers to the cultural differences in perceiving and experiencing time; for instance, a notion of time that is based on the beginning and end of social and environmental experiences rather than on arbitrary points of reference such as the clock-time that dominates U.S. culture. The orientation to temporal factors is more non-linear than the linear orientation of mainstream American culture. Rhythm, call and response, synchronization of self and 
environment implies a different organization of behavioral patterns within a given situation or time period. Improvisation encourages mastery of the function of a task and then applying the knowledge and skills creatively and intuitively in response to the demands, challenges, feedback (call and response); improvisation prefers flexibility over structure. The model also posits that in African culture, oral expression is a preferred means of exchanging social and historical information and expressing social intelligence. It's not just what you say, it is how you say it—style and substance (i.e. Griots, rappers, preachers, political leaders). Spirituality is described by Jones (1997) as the "belief in nonmaterial causation” and “measure of accomplishment not on earth” (p.39). What makes African American culture distinctive is not these individual elements, but rather the unique pattern they form as a whole. The discussion of distinct cultural elements such as these rarely suggest that these are features that African descendants posses exclusively, but they are important to consider because in many areas across the globe African descendants must continually adjust their cultural ethos in order to adapt in societies with the conflicting values of another, dominant culture. In addition to the conceptual culture-related literature on African Americans there has also been a moderate amount of empirical writing and measurement development, but this is certainly an area that needs more attention (McLoyd, 2004).

\section{Measuring racial and cultural constructs with adolescents}

Much of the research and instrument development has focused on college students and other adults. Indeed, the measurement and application of racial and cultural 
constructs with African American adolescents requires important and unique considerations.

The adolescent life stage begins near puberty, but the end of adolescence is much more variable and indistinct (Marcia, 1980). According to Marcia, adolescence “...is the first time that physical development, cognitive skills, and social expectations coincide to enable young persons to sort through and synthesize their childhood identifications in order to construct a viable pathway toward their adulthood” (Marcia, 1980, p.160).

Several measures have been developed to assess racial and cultural constructs specifically for African American adolescents (Resnicow et al., 1999; Stevenson, 1994). One such instrument, the Adolescent Survey of Black Life assesses three independent dimensions that are based on common themes reported in the literature: (1) beliefs about being Black, which include own-group preference, cultural pride, affinity for Black things, and Adoption of African centered values; (2) attitudes towards whites, which includes preferences for White friends, interracial dating and integrated neighborhoods; and (3) attitudes about racism (Resnicow et al., 1999). For further conceptual development of this scale, the authors recognize that one dimension, the pro-Black factor, “includes items that tap elements of U.S. Black experience as well as Afrocentric aspects of racial and ethnic identity" and they question whether or not "these dimensions should be considered discrete elements of racial and ethnic identity” (Resnicow et al., 1999, p. 184).

A prominent measure of adolescent racial socialization, Stevenson’s (1994) Scale of Racial Socialization for Adolescents (SORS-A), also recognized the importance of 
multidimensionality in accurately understanding this construct. Principal components analyses of the SORS-A revealed four factors: Spiritual and Religious Coping, Extended Family Caring, Cultural Pride Reinforcement, and Racism Awareness Teaching. These factors included a combination of protective and proactive racial socialization themes and they were found to be very meaningful and moderately reliable (Stevenson, 1994). In a study examining the relationship between racial socialization and racial identity Stevenson (1995) found that these four factors were related in conceptually predicable ways to three stages (pre-encounter, immersion, and internalization) of the aforementioned Nigrescence model of racial identity development.

Stevenson et al. (2002) further contributed to the assessment of adolescent racial socialization by developing a scale that measures youth’s actual experience with racial socialization. The previously discussed SORS-A primarily assesses beliefs, while the Teenager Experience of Racial Socialization (TERS) scale is designed to assess the frequency of the messages they have received or practices they have experienced from their parents or guardians (Stevenson et al., 2002). Results of analyses of this instrument revealed five factors (Cultural Coping With Antagonism, Cultural Pride Reinforcement, Cultural Legacy Reinforcement, Cultural Alertness to Discrimination, and Cultural Endorsement to the Mainstream) and initial findings suggest that boys are communicated more messages that alert them to discrimination than girls, and there was little association between the racial socialization experiences measured by the TERS and racial socialization beliefs measured by the SORS-A (Stevenson, Cameron, Herrero-Taylor \& Davis, 2002). 
Critical insights have been discovered and reported in the literature regarding the conceptualization of African American racial and cultural constructs such as identity, self-concept and socialization and worldview for adults and adolescents. The next important steps include the application of these constructs to relevant psychosocial outcomes. The following section specifically emphasizes outcomes that have been presented as indicators of positive youth development.

\section{Psychosocial Outcomes Related to Racial and Cultural Constructs}

Racial and cultural phenomena have been investigated as predictors, mediators, and moderators of a wide variety of outcomes for adults and adolescents. Some of the literature has identified positive relationships between aspects of racial identity and academic performance (Oyserman, D., Harrison, K., \& Bybee, D., 2001; Oyserman, D., Ager, J., \& Grant, L., 1995). Lockett and Harrell (2003) argue that too much has been inaccurately interpreted about the relationship between racial identity and academic performance; instead, they found that the relationship actually has much more to do with youth having higher self esteem in order to have a higher GPA.

The other major area of research in the literature has explored relationships between African American racial concepts and different facets of well-being. For instance, Allen and Stukes (1982) discovered an association between racial identification and positive outcomes such as increased tolerance of frustration, a stronger sense of purpose, and a greater security in self. Additionally, Caldwell et al. (2004) found that, particularly for males, racial identity attitudes buffered the effects of racial discrimination 
and violence, and Belgrave et al. (2000) reported associations between pro-Black attitudes and anti-drug attitudes.

There is a greater paucity of literature that examines, from a cultural perspective, relationships between African American identity/worldview and relevant psychosocial variables. Researchers interested in African-centered constructs and measures have explored outcomes that have more of an emphasis on well-being. Some of the outcomes that have been predicted by at least some dimension of an African-centered worldview include high self-esteem in females (Akbar, Chambers \& Sanders Thompson, 2001), low perceived stress (Chambers et al., 1998), and constructive coping strategies (Scott, 2003; Constantine, Donnelly \& Myers, 2002).

A summation of the major themes in psychology literature on race and culture

Despite the difficulty inherent in its complexity, a good amount of research and theory building has occurred in the interest of understating cultural and especially racial phenomenon for African Americans. There is disagreement with the definitions of these constructs, but it is widely agreed that both race and culture for African Americans involve multiple dimensions, are fluid, and are most accurately understood within larger social, political, historical, and economic contexts. One prominent theory describes four dimensions of racial identity: 1) racial salience, 2) the centrality of the identity, 3) positive regard for one's racial group, and 4) the ideology associated with the identity. (Sellers et al., 1998) Important research has also been done regarding racial socialization, the process whereby young people receive messages from their parents and guardians regarding race relations, discrimination, and empowerment. Racial orientation has been 
associated with positive outcomes such as academic success, anti-drug attitudes, and a stronger sense of purpose.

A related, but often separate camp of theorists and researchers has investigated the role of culture in the experiences of African Americans. This typically occurs within the framework of an African-centered perspective, which highlights the elements of traditional African values and worldview that continue to be present in contemporary African American culture. Critical elements of this African centered perspective include spirituality, and an extended sense of self that includes family, communities and nature. Much less empirical literature exists that applies African centered concepts. However, some studies have shown relationships between an African centered cultural orientation and outcomes such as high self esteem, low perceived stress, and positive coping mechanisms (Akbar, Chambers \& Sanders Thompson, 2001; Chambers et al., 1998; Scott, 2003).

The Present Study

This study seeks to investigate the presence and influence of a cultural orientation in African American adolescents. The first aim of this study is to determine whether cultural and racial attitudes held by African American adolescents represent two distinct dimensions: a racial orientation and a cultural orientation. The second aim of this study is to determine the unique influence of cultural orientation on a variety of indicators of positive youth development. Much of the empirical psychology literature limits its study to the relationship between racial constructs and various outcomes. The present study proposes that even when the contribution of race is accounted for, a cultural orientation 
will significantly add to the prediction of positive outcomes for African American adolescents. The author suggests the following hypotheses:

$\mathrm{H}_{1}$ : The racial and cultural orientations observed in African American adolescents are two distinct and individually reliable constructs.

$\mathrm{H}_{2}$ : In addition to the influence of racial orientation, adolescents' cultural orientation will serve as a unique, significant predictor of the following outcomes:
a. academic success
b. well-being
c. social skills
d. social-political efficacy
e. community and political involvement 


\section{METHODS}

\section{Participants}

The participants included in the present study were only the African American adolescents $(\mathrm{N}=174)$. Sixty percent of them were female. Most of the participants were between the age of 13 and 18. There were 2 twelve year olds and 2 nineteen year olds. The mean age was 15.24 ( $S D=1.47)$. Five participants were born outside of the US, but they still identified as African American. One participant added that they were from the West Indies (Trinidad).

Procedure

The present study used data collected for a study about youth sociopolitical development. The sample included 223 high school aged adolescents in the Atlanta area. Between February 2004 to November 2005 data were collected on adolescents from multiple venues. Approximately half the sample was obtained via purposive oversampling of youth who are active in their communities. To meet this goal, various youthfocused groups and organizations in the Atlanta area were identified as potential recruitment agencies who could nominate active young people who were eligible and interested in the study. The remainder of the sample consisted of young people who reported less involvement in community activism. These youth were primarily recruited via public and private high schools, as well as other social, sports, or church groups/events. 
After identifying and recruiting potential youth for participation the researchers offered incentives to both the sponsoring organizations and the adolescent participants. Incentives offered to organizations included workshops facilitated by research staff members on relevant youth related topics (i.e. critical consciousness of popular media and leadership development), and the opportunity to network and publicize their organization's work on a website that was created for this project (www.gsu.edu/youthnaction). However, it was made clear to each organization that youth should participate on a voluntary basis and not because of inducements to participate. Each youth received $\$ 7$ or a free movie pass and a chance to win a variety of prizes (valued up to $\$ 100$ ) through a drawing.

Several of the measures included in the survey packet were only given to the African American participants because there were a number of research questions in the larger study that were specific to the experiences of African American youth. Most of the adolescent participants completed the survey in small groups of approximately 10-25 people and all survey administrations were facilitated by trained research assistants. Any administrations to individual youth were supervised by an adult or research assistant. In the event that a youth participant was unable to read at the appropriate level to complete the survey on his/her own, research assistants were trained to adjust administration procedures accordingly, which included reading the items out loud to a single participant or small groups of participants. For individuals under the age of 18, parental consent was obtained. The surveys took approximately 40 minutes to complete.

\section{Measures}


The independent variables for this study were compiled from three separate measures of racial and ethnic identity and socialization. The goal was to distinguish between the racial and cultural orientation that items in these measures assessed. The method for deciding which items assessed racial orientation and which items assess cultural orientation is discussed in more detail below. The dependant variables were chosen from different measures included in the sociopolitical development survey. Table 1 outlines the measures that are associated with each specific outcome of interest. The table also includes the reliability coefficients (alpha) that were obtained using the current sample of adolescents. 
Table 1

Dependent Variables, the Measures Used to Assess Them and Their Reliability Coefficients

Outcome Components Measures

Academic Success: GPA (self report item)

Intellectual Curiosity $\quad$ Intellectual Curiosity Scale $(\alpha=.85)$

Well Being: Anxiety Brief Symptom Inventory $(\alpha=.80)$

Depression $\quad$ Brief Symptom Inventory $(\alpha=.83)$

Social Skills:

Social Skills Rating Scale ( $\alpha=.88$ )

Social Political

Policy Control

Social Political Control Scale ( $\alpha=.60)$

Efficacy:

Leadership

Competence

Perceived Control

Social Responsibility

Activism:
Community and

Political Involvement
Social Political Control Scale ( $\alpha=.38)$

Perceived Control Scale ( $\alpha=.58)$

Youth Social Responsibility Scale ( $\alpha=.75)$

Youth Inventory of Involvement $(\alpha=.86)$ 
Demographic Information. Participants were asked to report their gender, ethnicity, date of birth, grade, name of high school and other demographic variables.

Communalism Scale (Boykin, Jagers, Ellison \& Albury, 1997). This 31-item scale assesses the extent to which an individual espouses a social/relational belief system based on group and family interdependence and cooperation. Participants are asked to respond to statements such as "I am constantly aware of my responsibility to my family and friends” on a 6-point, Likert-type scale that ranges from "completely false” to “completely true.” Previous research has yielded alpha coefficients ranging from .83 to .88 (Jagers \& Mock, 1995; Mattis et al., 2000). All items were summed and then averaged, with lower scores indicating a more individual-based belief system that does not emphasize group and family interdependence.

Multidimensional Inventory of Black Identity (MIBI; Sellers, Rowley, Chavous, Shelton \& Smith, 1997). The development of this 51-item scale was guided by the Multidimensional Model of Racial Identity. Factor analysis was used by Sellers et al. (1997) to detect several dimensions: racial centrality, private regard, public regard (which was not included in this questionnaire) and four ideology subscales (Nationalist, Humanist, oppressed minority, and Assimilationist). The private regard subscale contains seven items that assess one's affective evaluation of being Black. The four ideology subscales contain nine items each and were assessed using a 7-point Likert-type scale ranging from strongly disagree to strongly agree. Participants responded to statements such as, "I have a strong sense of belonging to Black people" and "The racism Blacks have experienced is similar to that of other minority groups.” Patterns of 
responses on these items are typically used to determine which subscale or dimension of identity is frequently endorsed. The scales’ authors report coefficient alphas ranging from .60 to .79 .

The Social Skills Rating System (Gresham \& Elliot, 1990). This measure assesses domains of youth peer relationships and interactions. It was standardized on a national sample of over 4, 000 children and adolescents; it provides separate norms for boys and girls ages 3-18. The internal consistencies/test-retest reliabilities for social skills ratings are as follows: teacher ratings (93/.85); parent ratings (83/.68); and self ratings (.83/.68). This instrument comprises four subscales: Cooperation (10 items), Assertion (10 items), Self-Control (10 items), and Empathy (10 items). The current study utilized a summed score of all the subscales combined.

Intellectual Development A self-report inventory was developed to assess behaviors associated with intellectual curiosity and engagement. Sample items include following current events (e.g. TV, radio, print, internet), elective reading, elective conversations about politics, religion or current events with peers or adults, and intellectually challenging extracurricular activities/hobbies. An index of intellectual development was created by averaging these items. This measure demonstrated good reliability with the current sample $(\alpha=.85)$.

Sociopolitical Control Scale (Zimmerman \& Zahniser, 1991). This 17-item scale assesses the cognitive, motivational and personality dimensions of an individual's perceived level of sociopolitical control. This scale, in other words, measures the degree to which a person believes that actions in the social and political system can lead to 
desired outcomes. Two subscales - Leadership Competence and Policy Control - make up this psychometrically-validated scale: Previous research has yielded reliability coefficients of .78 to .79 for the Leadership Competence subscale and .74 to .75 for the Policy Control subscale (Zimmerman \& Zahniser, 1991; Itzhaky \& York, 2000). Items are rated on a 6-point Likert scale that ranges from "very strongly disagree” to "very strongly agree”. In the current sample the Policy Control and leadership Competence subscales yielded inadequate reliability coefficients ( $\alpha=.60$ and $\alpha=.38$, respectively), so a composite score was used for analyses that combined the two sub-scales. The total score was more reliable $(\alpha=.71)$.

\section{Scale of Racial Socialization for African American Adolescents (SORS-A)}

(Stevenson, 1994). The SORS-A was designed to assess and adolescent's opinion about the appropriateness of racial socialization processes in educational, family, and societal venues. One 9-item subscale from this instrument was administered called Cultural Pride and Reinforcement. This scale included items such as "Parents can teach children to be proud to be Black without saying a word” and participants responded on a scale from 1 (Strongly Disagree) to 5 (Strongly Agree).

Perceived Control Scale (PCS) - Community-Level (Schulz, Israel, Zimmerman, Checkoway, 1995). The perceived control scale assesses how much control a respondent feels over their social, physical and environment. The three subscales assess three different levels of control: individual, organizational, and community control. This study will use the Community-Level subscale of the PCS in order to measure the collective dimension of the Sense of Agency construct (i.e. collective efficacy and control). The 7- 
item scale included such items as "I can influence decisions that affect my community" and "People in my community work together to influence decisions on the state or national level.” Items are ranked on a 4-point scale that ranging from "strongly disagree” to “strongly agree”. Alpha coefficients for the Community-Level scale range from .81 (Becker, Israel, Schulz, Parker \& Klem, 2002) to .63 (Parker, Lichtenstein, Schulz, Israel, Steinman et al., 2001). However, a low reliability coefficient was obtained with the present sample $(\alpha=.58)$.

Youth Social Responsibility Scale (YSRS) (Pancer, Pratt \& Hunsberger, 2000). This scale was developed to assess teenagers' commitment to societal involvement, using such items as "More young people should become active in political parties and organizations" and "Young people have an important role to play in making the world a better place.” Each item is ranked on a 9-point Likert scale ranging from “very strongly disagree” (-4), to "very strongly agree” (+4). Alpha for the YSRS ranged from .85 to .87 among two samples of Canadian youth aged 16-19. Test-retest reliability over a two year period was .62.

Youth Inventory of Involvement (YII) (Pancer, Pratt \& Hunsberger, 2000). This 30-item scale was devised to assess type and amount of youth societal involvement behavior. Factor analysis was used by the authors to derive four subscales, each of which represents a different kind of societal involvement: political activities, community/neighborhood activities, helping activities, and responding activities. Respondents indicate how much, in the past year, they have participated in each of the activities using a 5-point scale that ranges from "I never did this over the past year" to "I 
did this a lot over the past year”. Based on two large samples of Canadian youth aged 1619, Alpha for the YII was.90 and test-retest reliability over two years was .61. For the current study community/neighborhood activities and political activities were combined and summed to create the outcome variable. Higher scores indicate more involvement.

Brief Symptom Inventory (BSI; Derogatis \& Spence, 1982). The Brief Symptom Inventory is designed to assess psychological symptoms. The BSI asks the respondent to report the extent to which he or she has been troubled in the past 7 days. This study will utilize a combination of two of the nine symptom profiles: depression and anxiety. Participants rated each item on a 5-point, Likert-type scale ranging from 0 (not at all distressed) to 4 (extremely distressed). All items were summed, with higher scores indicating more psychological distress. Internal consistencies have been found to be acceptable and have ranged from .71 (Somatization) to .85 (Depression) (Derogatis, 1993).

\section{Distinguishing Racial and Cultural Orientation}

One of the main aims of this proposal is to determine whether cultural and racial attitudes held by African American adolescents represent two distinct dimensions: a Racial Orientation and a Cultural Orientation. None of the measures included in this study were designed to capture dimensions of identity, socialization or worldview that are intentionally based on African-centered cultural paradigms. However, upon reviewing the scales the author found items that are consistent with this cultural frame of reference. Items were selected from Communalism scale (Boykin, Jagers, Ellison \& Albury, 1997), the Multidimensional Inventory of Black Identity (Sellers, Rowley, Chavous, Shelton \& 
Smith, 1997) and the Scale of Racial Socialization for Adolescents (Stevenson, 1994) that would typify an African-centered cultural orientation, based on psychological literature regarding culture with African Americans. For comparison purposes, items were also selected from these scales that would represent a racial orientation. However, to reduce bias in the selection of these items, the researcher sought assistance from independent judges $(\mathrm{N}=3)$ — clinical and community psychology graduate students. With each of the assisting graduate students, the researcher explained the project briefly and described the nature of the two orientations. Then the researcher asked the graduate students to sort each of the items accordingly. If they though an item belonged in the cultural orientation they wrote "C" next to it, if they thought the item belonged in the racial orientation they wrote an "R", and if they thought an item was not mutually exclusive (i.e. belonged in either category) they wrote an "N" to indicate "neither". Graduate assistant ratings were compared to those previously selected by the author. If an item was selected for the final category, that meant that at least two judges also sorted that item into the intended category (see Appendix A for a list of the final category sorting of items and the scales from which they were obtained). A complete list of ratings is listed in Appendix B.

\section{Data Analytic Procedure}

The initial exploratory factor analysis included all the items from the Communalism scale, the Multidimensional Inventory of Black Identity, and the Scale of Racial Socialization for Adolescents. The factor structure was explored through a principle components analysis using SPSS and a varimax rotation. Interpretation of the factor structure was based on the items selected by the author and colleagues to represent the cultural and racial orientations. Because the resulting factors are composed of items 
from existing measures with different response scales, the standardized values were used to create the factors used for further analyses.

Subsequently hierarchical multiple regression analyses were used to determine the unique influence of cultural orientation factors on a variety of youth outcome variables (Cohen, 2004). Using multiple regression, and constraining alpha to .05, to detect a medium effect of .15 with four independent variables a minimum sample size of 70 participants was needed, which the present study exceeds (Pedhazur and Schmelkin,1991). Demographic characteristics were entered into step 1 of the multiple regression analyses to control for the effects of gender and age on each outcome variable. In the second step, Racial Orientation was entered. In the third, and final step, Cultural Orientation was entered to assess this constructs' additional contribution in explained variance in youth outcomes. These steps were repeated for several different dependent variables (e.g. academic success, well-being, social skills, and social and political efficacy, activism), yielding nine different multiple regression analyses. 


\section{RESULTS}

Hypothesis One: The racial and cultural orientations observed in African American adolescents are two distinct and individually reliable constructs.

Principal components factor analysis was able to determine some meaningful differences between two cultural and racial orientation factors. A description of the process of obtaining those factors follows. Initially, all the items from the Communalism Scale, MIBI, and SORS-A were entered into the factor analysis. When all three scales were included, the principle components analysis produced factors that were conceptually inconsistent with the literature. Since the sample size is moderate $(\mathrm{N}=174)$ and there are a total of 57 items with all three scales included, the results from that original factor analysis had questionable validity.

The factor solution that was used for the multiple regression analyses was obtained by entering only the items from the MIBI and the SORS-A. The eigenvalue $>1$ criterion produced a 6 factor solution, which accounted for $53 \%$ of the variance in these items. A five factor model that is most meaningful for interpretation was derived from the original 6 factor solution The five factor model was evaluated based on its ability to: (1) satisfy Catell's (1966) scree plot test, (2) retain three or more items with salient loadings greater or equal to .50 , (3) include items that exclusively load on one factor, and (4) make conceptual sense based on the literature and the proposed model of cultural and racial 
orientations. Table 3 describes the five factors, their loadings, their respective eigenvalues, and alpha coefficients.

Table 2

Item Loadings, Eigenvalues, and Reliabilities of Principal Components Analysis

\begin{tabular}{|c|c|c|c|c|c|}
\hline Items & $\begin{array}{l}\text { Cultural } \\
\text { Heritage } \\
\end{array}$ & Integrationist & Multi-Racial & $\begin{array}{l}\text { Racial } \\
\text { Pride }\end{array}$ & $\begin{array}{l}\text { Cultural } \\
\text { Nationalist }\end{array}$ \\
\hline $\begin{array}{l}\text { Teachers should make it so } \\
\text { Black children can see signs } \\
\text { of Black culture in } \\
\text { classrooms. }\end{array}$ & .75 & .19 & -.13 & .13 & .11 \\
\hline $\begin{array}{l}\text { Schools should be required } \\
\text { to teach all children about } \\
\text { Black history. }\end{array}$ & .72 & .01 & 16 & .01 & .01 \\
\hline $\begin{array}{l}\text { Black parents should talk } \\
\text { about their roots to African } \\
\text { culture to their children. }\end{array}$ & .70 & 18 & .01 & 20 & .01 \\
\hline $\begin{array}{l}\text { Teaching children about } \\
\text { Black history will help them } \\
\text { to survive a hostile world. }\end{array}$ & .65 & .01 & 13 & .23 & .01 \\
\hline $\begin{array}{l}\text { Spiritual battles that people } \\
\text { fight are more important than } \\
\text { the physical battles. }\end{array}$ & .56 & .01 & .14 & .01 & 15 \\
\hline $\begin{array}{l}\text { Relatives can teach children } \\
\text { things that parents may not } \\
\text { know }\end{array}$ & .55 & 14 & .27 & .01 & .01 \\
\hline I am proud to be black. & .12 & .84 & .01 & .25 & .01 \\
\hline $\begin{array}{l}\text { Blacks should try to work } \\
\text { within the system to achieve } \\
\text { their political and economic } \\
\text { goals. }\end{array}$ & .11 & .76 & .34 & .10 & -.13 \\
\hline $\begin{array}{l}\text { Blacks should strive to } \\
\text { integrate all institutions that } \\
\text { are segregated. }\end{array}$ & .01 & .75 & .01 & .01 & 15 \\
\hline I am happy that I am Black. & .14 & .64 & .34 & 33 & .01 \\
\hline $\begin{array}{l}\text { Blacks would be better off if } \\
\text { they were more concerned } \\
\text { with the problems facing all } \\
\text { people than just focusing on } \\
\text { Black issues. }\end{array}$ & .01 & .22 & .73 & .01 & .14 \\
\hline $\begin{array}{l}\text { Blacks should have the } \\
\text { choice to marry other races }\end{array}$ & .17 & .01 & .62 & .14 & -.15 \\
\hline
\end{tabular}


Blacks should feel free to

interact socially with White

people.

Being Black is an important $\quad .34$

reflection of who I am.

The racism Blacks have

experienced is similar to that

of other minority groups.

I have a strong sense of

belonging to Black people.

I feel good about Black

people.

In general, being Black is an $\quad .32$

important part of my self-

image.

It is important for Black people to surround their children with Black art, music and literature.

Blacks would be better off if $\quad .01$

they adopted Afrocentric values.

White people can never be $\quad-.41$ trusted where Blacks are concerned.

Black people must organize themselves into a separate

Eigenvalues

8.57

.79

.01

Alpha Black political force.

.16

.23

.11

.18

.15

.20

.12

.01

.56

$.01 \quad .01$

$-.41 \quad .01$

$-.13$

.14

.12

.36

.01
3.13

.83
2.18

.76
.26

.61

.61

.01

.24

.01

.01

80

The five factor model corresponded with the racial and cultural domains discussed earlier. Factor 1, Cultural Heritage, includes items that promote spirituality and the value of the extended family. There are items that represent a connection to African roots and the importance of history as a tool for survival. Factor 2, Integrationist, has items that emphasize the need for African Americans to work within American political systems and institutions. This factor includes items about being proud of being African 
American, so this factor does not imply an interest in racial integration due to negative attitudes about being African American. Factor 3, Multi-Racial, has items that are more oriented towards engaging socially with other racial and cultural groups, but the pride items do not load on it strongly. The focus is on interracial similarities and common experiences, but with less emphasis on larger social systems. Factor 4, Racial Pride, encompasses items that emphasize positive affirmation of being Black and that part of a person's identity being central to their sense of self. Finally, factor 5, Cultural Nationalist, identifies a sub-set of items that represent a combination of African-centered cultural items, mistrust of Caucasian Americans and separatist political ideology.

Consistent with the cultural and racial categories created previously, the principal components analysis produced factors that represent cultural and racial orientations (see Table 4). The cultural factors are distinct because they are grounded in explicit and implicit African-centered cultural domains.

Table 3

Factors Organized by Orientation

Cultural Orientation

Cultural Heritage

Cultural Nationalist
Racial Orientation

Integrationist

Multi-Racial

Racial Pride

Each of the obtained factors yielded adequate internal consistencies, with the exception of the Cultural Nationalist factor $(\alpha=.59)$, leaving the Cultural Heritage factor as the sole representation of Cultural Orientation. Given the focus of this study on the 
cultural orientation dimension, the three racial factors were collapsed into one variable to represent Racial Orientation, and that variable demonstrated good internal consistency $(\alpha=.87)$. Table 5 shows the correlations among this final set of factors.

Table 4

$\underline{\text { Zero-Order Intercorrelations for Cultural and Racial Orientation Sub-Factors }}$

\begin{tabular}{|c|c|c|c|c|c|}
\hline Variable & 1 & 2 & 3 & 4 & 5 \\
\hline 1. Cultural Heritage & - & & & & \\
\hline 2. Cultural Nationalist & -.02 & - & & & \\
\hline 3. Integrationist & $.42 * *$ & .06 & - & & \\
\hline 4. Multi-Racial & $.35^{* *}$ & .19 & $.47 * *$ & - & \\
\hline 5. Racial Pride & $.48 * *$ & $.25 * *$ & $.53 * *$ & $.57 * *$ & - \\
\hline
\end{tabular}


Preliminary Descriptive Analysis

Descriptive statistics were computed for all variables in the analysis $(\mathrm{N}=174)$ in order to examine the distribution for outliers, and to assess the assumptions of multiple regression (i.e. linearity, independence, normalcy, and homogeneity). The descriptive values for all continuous variables used in the regression analyses are presented in Table 6.

Table 5

Descriptive Statistics for Continuous Variables on Regression Models

\begin{tabular}{|c|c|c|c|c|}
\hline \multirow[t]{2}{*}{ Variable } & \multicolumn{2}{|c|}{ Range } & \multirow[t]{2}{*}{ Mean } & \multirow[t]{2}{*}{ SD } \\
\hline & Minimum & Maximum & & \\
\hline Age & 13 & 18 & 15.24 & 1.47 \\
\hline Cultural Orientation & -1.89 & 1.10 & -.0004 & .70 \\
\hline Racial Orientation & -1.79 & 87 & -.1120 & .65 \\
\hline GPA & 0 & 5.00 & 3.37 & .54 \\
\hline Intellectual Curiosity & 0 & 5 & 2.65 & 1.04 \\
\hline Sociopolitical Control & 1.24 & 6.00 & 3.46 & .95 \\
\hline Perceived Control & 1.29 & 3.86 & 2.65 & .50 \\
\hline Community and Political Activities & 0 & 72 & 20.28 & 14.68 \\
\hline Social Responsibility & 2.10 & 3.79 & 2.93 & .42 \\
\hline Social Skills & 15 & 78 & 46.16 & 12.30 \\
\hline
\end{tabular}


Anxiety

0

4

1.13

.95

Depression

0

3.67

1.09

.90

\section{Correlations}

Prior to performing the regression analyses for Hypothesis 2, the author examined the interrelationships among the demographic variables, the predictor variables and the outcomes. Zero-order correlations are presented in Appendix C. As anticipated, Cultural Orientation was moderately related to Racial Orientation ( $\mathrm{r}=.51, \mathrm{p}<.01)$, but this correlation is not so high that it suggests that these are identical constructs (the shared variance is about 26\%). Gender and age were each correlated with several of the outcome variables, suggesting further examination. The adolescents' gender was significantly related to Community and Political Activities ( $\mathrm{r}=-.16, \mathrm{p}<.05)$, Social Responsibility $(\mathrm{r}=.18, \mathrm{p}<.05)$, and Depression $(\mathrm{r}=.15, \mathrm{p}<.05)$. Their age was significantly correlated with Cultural Orientation ( $\mathrm{r}=.19, \mathrm{p}<.05)$, Racial Orientation $(\mathrm{r}=.21, \mathrm{p}<.01)$, GPA $(\mathrm{r}=-.21, \mathrm{p}<.05)$, Community and Political Activities $(\mathrm{r}=-.21, \mathrm{p}<.01)$ and Social Responsibility ( $\mathrm{r}=.21, \mathrm{p}<.01)$. However, gender and age are not the focus of this study, so they will be included as covariates in the regression analyses until future research can examine the particular nature of the relationship between them and the outcome variables. 
Hypothesis Two: In addition to the influence of Racial Orientation, adolescents' Cultural Orientation will serve as a unique, significant predictor for varied outcomes. The results of each outcome variable are presented below.

Academic Success. Neither Racial Orientation nor Cultural Orientation explained a significant portion of the variance in GPA, but Cultural Orientation predicted Intellectual Curiosity. Beyond the Age, Gender, and the nominal effect of Racial Orientation, Cultural Orientation explained unique variance in Intellectual Curiosity. Albeit, the total amount of variance explained was very small (6\%). A summary of the results are presented in table 7.1.

Table 6.1

Hierarchical Regression Analysis Summary for Cultural and Racial Orientation Predicting Academic Success

\begin{tabular}{llllll}
\hline Outcome & Block/Step & $\underline{\mathrm{B}}$ & $\underline{\mathrm{R}}^{2}$ & $\Delta \underline{\mathrm{R}}^{2}$ & $\Delta \underline{\mathrm{F}}$ \\
\hline GPA & Step 1 & & .092 & & $6.121^{* *}$ \\
& Gender & $.206^{*}$ & & & \\
& Age & $-.207^{*}$ & & & \\
& Step 2 & & .110 & .018 & 2.404 \\
& Gender & $.202^{*}$ & & & \\
& Age & $-.237^{* *}$ & & & \\
& Racial Orientation & .137 & & & \\
& Step 3 & & .120 & .010 & 1.420 \\
& Gender & $.199^{*}$ & & & \\
& Age & $-.225^{*}$ & & & \\
& Racial Orientation & .196 & & & \\
& Cultural & -.120 & & & \\
& Orientation & & & & \\
& Step 1 & & .001 & & .061 \\
Intellectual Curiosity & Gender & .026 & & &
\end{tabular}


Table 6.1

Hierarchical Regression Analysis Summary for Cultural and Racial Orientation Predicting Academic Success

\begin{tabular}{llllll}
\hline Outcome & Block/Step & $\underline{\mathrm{B}}$ & $\underline{\mathrm{R}}^{2}$ & $\Delta \underline{\mathrm{R}}^{2}$ & $\Delta \underline{\mathrm{F}}$ \\
\hline Age & .009 & & & \\
Step 2 & & .008 & .007 & 1.127 \\
Gender & .021 & & & \\
Age & -.010 & & & \\
& Racial Orientation & .087 & & & \\
Step 3 & & .061 & .053 & $8.679 * *$ \\
& Gender & .032 & & & \\
Age & -.031 & & & \\
Racial Orientation & -.048 & & & \\
Cultural & $.269 * *$ & & & \\
& Orientation & & & & \\
\hline
\end{tabular}

${ }^{* *} p<.01,{ }^{*} p<.05$

Well Being. Higher scores on the Racial Orientation factor predicted less anxiety and depression for the youth in this sample $\left(\mathrm{R}^{2}=.15\right.$ and .16 , respectively), while Cultural Orientation did not have a significant impact (see Table 7.2).

Table 6.2

Hierarchical Regression Analysis Summary for Cultural and Racial Orientation Predicting Well Being

\begin{tabular}{llllll}
\hline Outcome & Block/Step & $\underline{\mathrm{B}}$ & $\underline{\mathrm{R}}^{2}$ & $\Delta \underline{\mathrm{R}}^{2}$ & $\Delta \underline{\mathrm{F}}$ \\
\hline Anxiety & Step 1 & & .015 & & 1.183 \\
Gender & -.062 & & & \\
Age & -.101 & & & \\
Step 2 & & .147 & .132 & $24.111^{* *}$ \\
Gender & -.043 & & & \\
Age & -.020 & & & \\
Racial Orientation & $-.373^{* *}$ & & & \\
Step 3 & & .151 & .004 & .720
\end{tabular}




$\begin{array}{ll}\text { Gender } & -.046 \\ \text { Age } & -.015 \\ \text { Racial Orientation } & -.336^{* *} \\ \text { Cultural } & -.074 \\ \text { Orientation } & \end{array}$

Depression

\begin{tabular}{lllll} 
Step 1 & & .013 & & 1.009 \\
Gender & -.009 & & & \\
Age & -.112 & & & \\
Step 2 & & .163 & .150 & $28.042^{* *}$ \\
Gender & .010 & & & \\
Age & -.026 & & & \\
Racial Orientation & $-.398^{* *}$ & & & \\
Step 3 & & .168 & .004 & .822 \\
Gender & .007 & & & \\
Age & -.020 & & & \\
Racial Orientation & $-.359 * *$ & & & \\
Cultural & -.078 & & & \\
Orientation & & & & \\
\hline
\end{tabular}

${ }^{* *} p<.01,{ }^{*} p<.05$

Social Skills. The standardized Beta coefficient at step two $(B=.411, \mathrm{p},<.01)$ suggested that higher scores on the Racial Orientation factor were indicative of greater social skills in adolescents. Cultural Orientation explained an additional, unique 7\% of the variance in Social Skills (see Table 7.3).

Table 6.3

Hierarchical Regression Analysis Summary for Cultural and Racial Orientation Predicting $\underline{\text { Social Skills }}$

\begin{tabular}{llllll}
\hline Outcome & Block/Step & $\underline{\mathrm{B}}$ & $\underline{\mathrm{R}^{2}}$ & $\Delta \underline{\mathrm{R}}^{2}$ & $\Delta \underline{\mathrm{F}}$ \\
\hline Social Skills & Step 1 & & .006 & & .475 \\
& Gender & .019 & & & \\
Age & .074 & & & \\
& Step 2 & & .166 & .160 & $29.960^{* *}$ \\
Gender & -.001 & & & \\
Age & -.015 & & & \\
Racial Orientation & $.411^{* *}$ & & & \\
& Step 3 & & .237 & .071 & $14.371^{* *}$
\end{tabular}




$\begin{array}{ll}\text { Gender } & .011 \\ \text { Age } & -.039 \\ \text { Racial Orientation } & .254^{* *} \\ \text { Cultural Orientation } & .312^{* *}\end{array}$

${ }^{* *} p<.01,{ }^{*} p<.05$

Social-Political Efficacy. The final step, when both orientations are included, accounted for a small portion of the variance in Perceived Control $\left(\mathrm{R}^{2}=.08, \mathrm{p}<.01\right)$, but Cultural Orientation contributes positively, uniquely, and significantly, whereas Racial Orientation was not significant. The reverse was true for Sociopolitical Control as Racial Orientation was the significant contributor $\left(B=-.374, \mathrm{p}<.01, \mathrm{R}^{2}=.13\right)$. In step two of the hierarchical regression, Racial Orientation contributes significantly to predicting Social Responsibility $(B=.302, \mathrm{p}<.01)$. The influence Racial Orientation becomes nonsignificant in the final step when Cultural Orientation is added. Cultural and Racial Orientations explain 31\% of the variance in Social Responsibility, 13\% of that uniquely contributed by Cultural Orientation (see Table 7.4).

\section{Table 6.4}

Hierarchical Regression Analysis Summary for Cultural and Racial Orientation Predicting Social Political Efficacy

\begin{tabular}{llllll}
\hline Outcome & Block/Step & $\underline{\mathrm{B}}$ & $\underline{\mathrm{R}^{2}}$ & $\Delta \underline{\mathrm{R}}^{2}$ & $\underline{\underline{\mathrm{F}}}$ \\
\hline Sociopolitical Control & Step 1 & & .008 & & .663 \\
& Gender & .084 & & & \\
& Age & .030 & & & \\
& Step 2 & & .125 & .117 & $20.884^{* *}$ \\
& Gender & .102 & & & \\
Age & .106 & & & \\
Racial Orientation & $-.351^{* *}$ & & & \\
Step 3 & & .127 & .001 & .263 \\
& Gender & .103 & & & \\
Age & .102 & & & \\
Racial Orientation & $-.374^{* *}$ & & & \\
Cultural & .045 & & &
\end{tabular}




\begin{tabular}{|c|c|c|c|c|c|}
\hline \multirow{14}{*}{ Perceived Control } & \multicolumn{5}{|l|}{ Orientation } \\
\hline & \multicolumn{2}{|l|}{ Step 1} & \multicolumn{2}{|l|}{.003} & \multirow[t]{2}{*}{.233} \\
\hline & Gender & .010 & & & \\
\hline & Age & -.054 & & & \\
\hline & Step 2 & & .020 & .017 & 2.630 \\
\hline & Gender & .004 & & & \\
\hline & Age & -.082 & & & \\
\hline & Racial Orientation & .132 & & & \\
\hline & Step 3 & & .080 & .061 & $10.151^{* *}$ \\
\hline & Gender & .017 & & & \\
\hline & Age & -.104 & & & \\
\hline & Racial Orientation & -.012 & & & \\
\hline & Cultural & $.288 * *$ & & & \\
\hline & Orientation & & & & \\
\hline \multirow[t]{13}{*}{ Social Responsibility } & Step 1 & & .085 & & $7.332^{* *}$ \\
\hline & Gender & .146 & & & \\
\hline & Age & $.242 * *$ & & & \\
\hline & Step 2 & & .172 & .086 & $16.287^{* *}$ \\
\hline & Gender & .131 & & & \\
\hline & Age & $.177 *$ & & & \\
\hline & Racial Orientation & $.302 * *$ & & & \\
\hline & Step 3 & & .306 & .134 & $29.853 * *$ \\
\hline & Gender & $.149 *$ & & & \\
\hline & Age & $.144^{*}$ & & & \\
\hline & Racial Orientation & .086 & & & \\
\hline & Cultural & $.429 * *$ & & & \\
\hline & Orientation & & & & \\
\hline
\end{tabular}

${ }^{* *} p<.01,{ }^{*} p<.05$

Community and Political Involvement. Cultural Orientation adds less than $1 \%$ of the explanatory contribution to predicting youth involvement behaviors. Instead, Racial Orientation predicted a lower frequency of youth involvement in community and political activities $(B=-.224, \mathrm{p}<.05)$. A summary of the results are presented in Table 7.5.

Table 6.5

Hierarchical Regression Analysis Summary for Cultural and Racial Orientation Predicting Community and Political Involvement

\begin{tabular}{llllll}
\hline Outcome & Block/Step & $\underline{\mathrm{B}}$ & $\underline{\mathrm{R}}^{2}$ & $\Delta \underline{\mathrm{R}}^{2}$ & $\Delta \underline{\mathrm{F}}$ \\
\hline
\end{tabular}




\begin{tabular}{llllll}
\hline Community and & Step 1 & & .071 & & 5.968 \\
& Gender & & & \\
& Age & -.143 & & & \\
Step 2 & $-.214^{* *}$ & & & \\
& Gender & & .110 & .039 & $6.918^{* *}$ \\
Age & -.133 & & & \\
Racial Orientation & $-.170^{*}$ & & & \\
Step 3 & $-.204^{* *}$ & & & .212 \\
Gender & -.131 & & .001 & \\
Age & $-.173^{*}$ & & & \\
Racial Orientation & $-.224^{*}$ & & & \\
Cultural & .041 & & & \\
Orientation & & & \\
\hline
\end{tabular}




\section{Additional Results}

Demographic Variables. Secondarily, noteworthy findings were revealed concerning the adolescent's gender and age. For instance, neither Cultural Orientation nor Racial Orientation accounted for a significant amount of the variance in an important indicator of academic success, GPA. Instead, the standardized Beta coefficients for Age $(B=.20, \mathrm{p}<.05)$ and Gender $(B=-.26, \mathrm{p}<.05)$ were significant even in the final step of the model with all variables included. The direction of the coefficients indicate that females and younger participants have higher GPA's. Results also suggest that as youth become older they feel more socially responsible, but they spend less time engaging in community and political activities. Despite significance in some instances, Age and Gender together did not explain more than $10 \%$ of the variance in any of the study's outcomes.

\section{Summary}

Table 8 highlights the differences in how the cultural and racial orientation factors were related to psychosocial and sociopolitical variables of interest. The only outcome that neither Cultural Orientation nor Racial Orientation predicted was student's grade point average in school. Otherwise, either factor independently or both factors together explained a significant amount of the variance in outcomes of interest. Cultural Orientation alone predicted adolescents’ Intellectual Curiosity and Perceived Control. Racial Orientation alone predicted Anxiety, Depression, Sociopolitical Control, and Community and Political Involvement. Both Cultural and Racial Orientations significantly predicted variance in adolescent Social Skills development. With Social 
Responsibility as an outcome, Racial Orientation was a significant predictor when

included in the hierarchical regression alone, but when Cultural Orientation was included, Racial Orientation was no longer significant, suggesting a possible mediating relationship.

Table 7

$\underline{\text { Summary of Differential Contribution of Cultural and Racial Orientation }}$

\begin{tabular}{|c|c|c|}
\hline Outcome & CO’s Contribution & RO’s Contribution \\
\hline \multicolumn{3}{|l|}{ Academic Success } \\
\hline GPA & None & None \\
\hline Intellectual Curiosity & Significant and Unique & None \\
\hline \multicolumn{3}{|l|}{ Well-Being } \\
\hline Anxiety & None & Significant and Unique \\
\hline Depression & None & Significant and Unique \\
\hline Social Skills & Significant & Significant \\
\hline \multicolumn{3}{|l|}{ Social-Political } \\
\hline \multicolumn{3}{|l|}{ Efficacy } \\
\hline Sociopolitical Control & None & Significant and Unique \\
\hline Perceived Control & Significant and Unique & None \\
\hline Social Responsibility & Significant and Unique & Significant \\
\hline Community and & None & Significant and Unique \\
\hline Political Involvement & & \\
\hline Totals & $\begin{array}{l}3 \text { significant and unique, } 1 \\
\text { significant, } 4 \text { no contribution }\end{array}$ & $\begin{array}{l}3 \text { significant and unique, } 2 \\
\text { significant, } 3 \text { no contribution }\end{array}$ \\
\hline
\end{tabular}




\section{DISCUSSION}

This study is a step towards elucidating the nature of cultural and racial orientation in African American adolescents. Recent research has focused on a multidimensional approach to understanding racial and ethnic phenomena such as identity, socialization, and worldview (Cokley, Helm, 2001; Walsh, 2001; SandersThompson, 2001; Sellers, et al., 1998). This study emphasized the importance of specific culture-related dimensions and the different roles cultural and racial orientation play in predicting youth development outcomes.

The literature in psychology offers many definitions and conceptualizations of racial and cultural terms (Phinney, 1996; Helms, 1997). Thus, the first aim of this study was to clarify the extent to which race-related research could be enhanced by distinguishing it from culture. Findings from the principal components factor analysis offer some support this study’s first premise that the two play different roles in youth development. African American adolescents responded to identity and socialization questions in a manner that suggested meaningful differences between racial and cultural orientation. The cultural orientation factor derived from this analysis was consistent with the African-centered psychology literature (Akbar, 1995; Nobles, 1986; Azibo, 1996; Kambon, 1992; Hilliard, 1997; Myers, 1988; Baldwin and Bell, 1985). More specifically, adolescents who scored high on the cultural orientation endorsed many core elements of 
an African-centered worldview, such as spirituality (Nobles, 1998), the extended family (Azibo, 1996), and a grounding in African heritage (Myers and Haggins, 1998) This represents 3 out of the 5 themes in African culture described in the introductory literature review.

These findings also suggest that the adolescents can endorse African-centered cultural values without necessarily identifying them as "African” or being familiar with Africentric terminology. The one item that made explicit reference to an African-centered framework (e.g. “Blacks would be better off if they adopted Afrocentric values”) did not load on the cultural orientation factor. This item loaded instead on the factor described as Cultural Nationalist. However, because of this factor's low internal consistency it was not included in the analyses. If some African American adolescents have negative associations with the continent of Africa, tapping into these cultural paradigms may be accomplished more effectively if approached implicitly. A much simpler and equally plausible explanation is that many of the youth in this sample were unfamiliar with the term 'Afrocentric' and consequently could not endorse it.

Similarly, the items loading on the Racial Orientation dimension were consistent with previous research on racial identity and socialization. The Racial Pride factor was similar to Sellers’ positive regard dimensions (Sellers, 1998), although this factor included an item that highlighted the importance of surrounding children with Black art, music and literature, which suggests a similar to Sanders-Thompson’s (2001) cultural racial identity dimension. The Integrationist factor was similar to Sellers'(1998) assimilationist dimension, but it included some of the political items. The Multi-Racial 
factor had one item that was similar to Sellers’ oppressed minority dimension, but most of the items promoted more emphasis on intergroup relations and contact. The results of the factor analysis suggest that racial and cultural constructs are not always mutually exclusive. To some extent, the overlap parallels that seen in literature on culture and race.

Exactly how distinct is cultural orientation from racial orientation? This remains an open question. In this study, the Racial Orientation factors were only moderately related to the elements of an African-centered cultural worldview as discussed in the literature review. In one of the few studies that examined the unique influence of racial and cultural dimensions found no relationship between their two dimensions (Allen \& Bagozzi, 2001). This is inconsistent with findings from the present study, where racial and cultural orientations were moderately correlated ( $\mathrm{r}=.51)$. Given that oppression can create pressure for cultural adaptation, some correlation seems likely. This can be seen in examples as simple as African American "soul” food, which is part of African American culture, but it originates in part from an adaptation to racial oppression during the slavery.

The second aim of this study was to explore the differential impact of culture and race on youth development outcomes. For some, but not all, of the youth development outcome variables there was support for the hypothesis that cultural orientation accounts for a significant portion of the variance in key outcomes beyond the effect of race. For instance, cultural orientation predicted higher scores on intellectual curiosity while racial orientation had no influence. Similarly, Boykin et al. (2005) suggest a relationship between “Afrocultural themes” and perceptions of academic success in their study 
involving low-income African American youth. In addition, Allen-Meares (1999) suggest there are "cultural contradictions" that exist in many urban school settings that occur when African American students are unable to relate their cultural heritage to their classroom experiences.

Unlike the findings for racial orientation, higher scores on cultural orientation were associated with an increased tendency to feel responsible for other people in one's social and community networks. This finding is consistent with a major component of an African-centered cultural orientation, communalism, which emphasized interdependence (Azibo, 1996; Boykin, Jagers, Ellison \& Albury, 1997). Both cultural and racial orientation predicted higher ratings on a social skills measure. Much of the literature regarding social skills for African American youth focuses on aggressive behaviors, isolation and other problems (Farmer, Estell \& Bishop, 2003; Olmeda \& Kaufman, 2003; Cooley \& Triemer, 2002). In other words, there continues to be a prominent deficit-based approach to understanding social skills for African American youth, and these findings suggest that there is something particular about African American's experience, culturally and racially, that facilitates social skill development. There is no obvious reason why cultural and racial orientation predicted the two political and community efficacy outcomes so differently. Racial orientation predicted sociopolitical control and cultural orientation predicted perceived control. Unlike sociopolitical control, perceived control is a measure of more local neighborhood and community efficacy. None of the theoretical ideas advanced for this study explains these findings. Because many comparisons were made for this exploratory study, there is always the possibility of Type 
I error. For this reason it is best to limit speculation on findings that bear no clear relationship to existing theory.

The second hypothesis was also not supported for other outcomes that racial orientation predicted but cultural orientation did not predict. For example, higher scores on racial orientation were associated with lower levels of depression and anxiety. In a previous study about coping resources, Spencer et al. (2003) had a hypothesis similar to the present study, that increased cultural socialization and spirituality would contribute to greater well being for African American youth. This, in fact was true, for the males and not the females in the Spencer et al. study. The sample for the present study consisted of majority females, so there may be important ways that young African American women conceptualize their cultural orientation that researchers have been unable to adequately measure. Alternatively, it may be true that racial orientation serves as a buffer against depression and anxiety in ways that cultural orientation is less effective.

Finally, higher scores on racial orientation were associated with lower levels of community and political involvement for youth in this sample. Much of the existing literature about community activism suggests that most community involvement behaviors for African Americans occur through religious institutions (Moore, 2003; Brown \& Brown, 2003; Mattis et al., 2000). However, church involvement is typically service oriented and rarely is it very politically oriented. More research is needed to understand the motivations of African American youth to engage in more politically orientated civic involvement. 
There were additional findings that were not related to this study's major aims that are worthy of noting. For instance, correlational findings suggest that adolescents are more likely to have higher values on both the Cultural and Racial Orientations as they become older. Participants in the current sample were as young as 13 and 14, which may be too young to for the abstract thinking necessary to think politically about race and apply this thinking to the items about race, culture, and sociopolitical concerns.

Implications for Practice and Research

The findings in this study have several implications for research. There is a paucity of empirical theory development literature utilizing cultural constructs for African American adolescents. Findings from this study suggest that there is value to considering and even focusing on African-centered cultural paradigms. Future research should focus initially on clarifying the theoretical relationship between culture and race. The next goal should be to develop empirically valid measures that intentionally assess African American adolescent's cultural orientation. Measurement development would benefit from qualitative procedures initially; individual internalization of transmitted cultural values involves a variety of intricate dynamics. Qualitative analyses could also incorporate the necessary considerations for adolescents’ level of maturation and their ability to interpret and express abstract ideas.

Additionally, future research should determine if there are any unique effects of race or culture on theoretically relevant developmental outcomes. For instance, if researchers were clearer about what core elements distinguish a racial orientation from a 
cultural orientation then it would be easier to make predictions about whether it makes sense for racial or cultural orientation to protect against anxiety and depression.

There are also several implications of this study's findings on psychological service provision. Due to the myriad of disparities among African American adolescents and other youth (Jones, 1997) many intervention and research programs seek to foster positive development of African American youth. Interventions and research often consider the salience of race for these youth. In general, much less is known about how culture influences positive African American adolescent development. The findings of this study point to several areas where culture may have a significant impact. For instance, a great deal of empirical support has been found for the premise that promoting positive racial identity will result in better academic performance (Oyserman, D., Harrison, K., \& Bybee, D., 2001; Oyserman, D., Ager, J., \& Grant, L., 1995) The findings from this study suggest that there is an association between cultural attitudes and intellectual development. For this reason it may more productive to expose youth to culture-enriching rites of passage programs, and books or documentaries about African culture in order to stimulate their intellectual development. Further, African American youth who are socially isolated or engage in interpersonal conflicts might benefit from programs that expose them to cultural interventions that emphasize interdependence and other African centered cultural values due to the finding that cultural orientation was related to social skills. Similarly, cultural orientation was associated with participation in community programs and service activities which may be influenced by a perceived responsibility for others in the community. Brookins and Robinson’s (1995) incorported many of these consideration into a rites of passage program for African American 
adolescents that has successfully equipped these youth with healthy resistance and coping strategies for navigating a society that is often discriminating and demeaning to them.

Conversely, this study's findings suggest that programs interested in reducing negative psychological consequences, such as anxiety and depression, should focus on promoting positive racial identity and socialization. Also, programs should focus on racial identity if they aim to develop youth who feel competent in leadership positions and feel confident in their ability to influence political processes.

Therefore, depending on the desired outcome some interventions may need to focus on the experiences of African Americans in America and consider all of the relevant race-related social, political and historical contexts. Other interventions may need to focus on broader historical experiences of African Americans and the common worldview they share with diasporic Africans, such as spirituality and extended sense of self, and other cultural values. Regardless, of the particular orientation and outcome relationships, the findings do demonstrate that the role culture plays has been underestimated. Thus, it may no longer be optimal for policies and institutions that serve African American adolescents to solely highlight race-related concerns. That might translate, for example, into Black history programs and courses in school incorporating more than African American s/heroes and American civil rights struggles. Instead, there would be more exposure to traditional and contemporary African culture and their similarities to the adolescents’ present day culture.

In sum, the findings of this research do not suggest that culture is important and race is not. Instead, since most research and intervention programs have focused 
primarily on race, the finding of this study suggest that there may be some value to investigating cultural phenomenon and incorporating them into interventions that seek to facilitate the positive development of African American youth.

\section{Strengths and Limitations}

Some of the strengths of this study include the diversity of the sample, the internal consistency of the measures, and the conceptually meaningful support of the factor analytic structure. African Americans are a very diverse and multifaceted population and many researchers generalize findings to this population based on samples obtained from one site. The sample for this study included youth from approximately 20 schools or organizations that ranged in location and purpose. This allows for greater generalizability to a broader population of Black youth. Additionally, the internal consistency of scales used in this study ranged from .75 to .88 with the exception of two sub-scales that weren't included in analyses (Leadership Competence and Policy Control) and Perceived Control $(\alpha=.58)$. Finally, this study did not rely on the researcher's delineation of items into the desired cultural and racial dimensions, even though a confirmation procedure was employed with other graduate student colleagues. Instead, this study relied on empirically validated factors categorized using principal components analysis. The factor analysis makes a stronger argument for distinguishing cultural dimensions from the racial ones.

Limitations of this study include the use of secondary data, and including questionnaires with adolescents that were created for adults. The survey used in this study was not created to explore the cultural and racial contributions to youth outcomes. 
Therefore, the researcher was limited to the outcomes assessed in the preexisting survey and to the measures in the questionnaire that were already designed to assess different dimensions of racial and cultural development. In addition, the items included from the SORS-A were designed to be used by adolescents, but the items used from the MIBI were not. Special considerations may be necessary for interpreting results from adolescents.

Despite the complications of accurately understanding racial and cultural identity, socialization and worldview among African American adolescents, it is the authors' hope that this study moves psychological research towards the direction of elucidating the nature of how race and culture operate and interact. Specifically, this study highlights the often underestimated importance of culture on understanding and enhancing the development of African American adolescents. If nothing else, this study suggests that culture is important, and although it is complicated it is something that warrants more attention that it has received. 


\section{References}

Allen, R.L., \& Bagozzi. (2001). Consequences of the Black self. Journal of Black Psychology, 27(1), 3-28.

Allen, W. \& Stukes, S. (1982). Black family lifestyles and the mental health of Black Americans. In F. Munoz \& R. Endo (Eds.), Perspectives on minority mental health. Washington, DC: University Press of America.

Allen-Meares, P. (1999). African American males: Their status, educational plight, and the possibilities for their future. In L. E. Davis (Ed.). Working with African American males: A guide to practice (pp. 117-128). Thousand Oaks, CA: Sage

Akbar, M, Chambers Jr., J.W., \& Sanders-Thompson, V.L. (2001). Racial identity, Africentric values and self-esteem in Jamaican children. Journal of Black Psychology, 27(3), 341-358.

Akbar, N. (1996). African metapsychology of human personality. In D.A. Azibo (Ed.) African Psychology in Historical Perspective and Related Commentary, Trenton NJ: Africa World Press, Inc.

Akbar, N.. (1995). Light from Ancient Africa. Tallahassee, Florida: Mind Productions and Associates.

Ani, M. (1980). Let the circle be unbroken. New York: Nkonimfo Publications.

Asante, M. (1980). Afrocentricity: The Theory of Social Change. Buffalo, NY: Amulefi 
Publishing Company.

Azibo, D.A. (1996). Mental health defined Africentrically. In D.A. Azibo (Ed.) African Psychology in Historical Perspective and Related Commentary, Trenton NJ: Africa World Press, Inc.

Baldwin, J.A. and Bell, Y.R. (1985). The African Self-Consciousness Scale: An Africentric Personality Questionnaire. The Western Journal of Black Studies, 9 (2), 59-68.

Belgrave, F.Z., Brome, D.R., \& Hampton, C. (2000). The contribution of Africentric values and racial identity to the prediction of drug knowledge, attitudes, and use among African American youth. Journal of Black Psychology, 26(4), 386-401.

Betancourt, H., \& Lopez, S. R. (1993). The study of culture, ethnicity,a nd race in American psychology. American Psychologist, 48(6), 629-637.

Boykin, A.W., Jagers, R.J., Ellison, C. \& Albury, A. (1997). The Communalism Scale: Conceptualization and measurement of an Afrocultural social ethos. Journal of Black Studies, 27, 409-418.

Boykin, A.W., Albury, A., Tyler, K.M., Hurley, E.A., Bailey, C.T., \& Miller, O.A. (2005). Culture-based perceptions of academic achievement among low -income elementary students. Cultural Diversity \& Ethnic Minority Psychology, 11(4).

Brookins, C.C. (1994). The relationship between Afrocentric values and racial identity attitudes: Validation of the Belief Systems Analysis Scale on African American 
college students. Journal of Black Psychology, 20(2), 128-142.

Brown, R. K. \& Brown, R. E. (2003). Faith and works: Church-based social capital resources and African American political activism. Social Forces, 82(2). 617-641.

Caldwell, C.H., Kohn-Wood, L.P., Schmeelk-Cone, K.H., Chavous, T.M., \& Zimmerman, M.A. (2004). Racial discrimination and racial identity as risk or protective factors for violent behaviors in African American young adults. American Journal of Community Psychology, 33(1/2), 91-105.

Chambers Jr., J.W., Kambon, K., Birdsong, B.D., Brown, J., Dixon, P., \& RobbinsBrinson, L. (1998). Africentric cultural identity and the stress experience of African American college students. Journal of Black Psychology, 24 (3), 368-396.

Chang, H. \& Dodd, T. (Spring, 2001). International perspectives on race and ethnicity: An annotated bibliography. In Electronic Magazine of Multicultural Education [online journal].

Cohen, Barry H.(2004).Essentials of statistics for the social and behavioral science. Hoboken, NJ : Wiley.

Cokley, K.O. and Helm, K. (2001) Testing the construct validity of scores on the multidimensional inventory of Black identity. Measurement and Evaluation in Counseling and Development, 34 (2), 80-99. 
Constantine, M., Donnelly, P.C., and Myers, L.J. (2002). Colective self-esteem and africultural coping styles in African American adolescents. Journal of Black Studies, 32 (6).

Cooley, E.L. \& Triemer, D.M. (2002). Classroom behavior and the ability to decode nonverbal cues in boys with severe emotional disturbance. Journal of Social Psychology, 142(6), 741-751.

Cross, W.E. Jr. (1971). The Negro to Black conversion experience. Black World, 20, 1327.

Derogatis, L. R., \& Spencer, P. M. (1982). The Brief Symptom Inventory (BSI):

Administration, and procedures manual-I. Baltimore, MD: Clinical Psychometric Research.

Farmer, T.W., Estell, D.B., \& Bishop, J.L. (2003). Rejected bullies or popular leaders? The social relations of aggressive subtypes of rural African American early adolescents. Developmental Psychology, 39(6), 992-1004.

Grills, C. \& Longshore, D. (1996). Africentrism: Psychometric analyses of a self-report measure. Journal of Black Psychology, 22, 86-106.

Gresham, F., \& Elliott, S. (1990). The Social Skills Rating System (SSRS). American Guidance Service, Inc., Circle Pines, MN.

Helms, J.E. (1994). The conceptualization of racial identity and other "racial” constructs. In E.J. Trickett, R.J. Watts, and D. Birman (Eds.) Human Diversity: Perspectives 
on People in Context. San Francisco, CA: Jossey-Bass.

Helms, J.E. \& Talleyrand, R.M. (1997). Race is not ethnicity. American Psychologist, 52(11), 1246-1247.

Hilliard, A. G. (1997). SBA: The reawakening of the African mind. Gainsville, FL: Makare Publisher.

Jagers, R. J. \& Mock, L. O. (1995). The Communalism Scale and collectivisticindividualistic tendencies: Some preliminary findings. Journal of Black Psychology, 21, 153-167.

Jones, J. (1997). Prejudice and Racism. The McGraw-Hill Companies: New York.

Kambon, K. (1996). The Africentric paradigm and African American psychological liberation. In D.A. Azibo (Ed.) African psychology in historical perspective and related commentary (pp.57-69). Trenton: Africa World Press.

Kambon, K. (1992). The African personality in America: An African centered framework. Tallahassee: Nubian Nation Publications.

Karenga, R. (1968). Black cultural nationalism. Negro Digest, 13(3), 5-9.

Klien, R.B. (1998). Measurement Models and Confirmatory Factor Analysis. In R.B. Klein (Ed.), Principles and Practice of Structural Equation Modeling. (pp.189243). New York: Guilford Press.

Kwate, N.O. (2003). Cross-validation of the Africentrism Scale. Journal of Black Psychology, 29(3), 308-324 
Lockett, C.T. \& Harrell, J.P. (2003). Racial identity, self-esteem, and academic achievement: Too much interpretation , too little supporting data. Journal of Black Psychology, 29(3), 325-336.

Marcia, J.E. (1980). Identity in adolescence. In J. Adelso (Ed.), Handbook of adolescent psychology (pp.159-187). New York: Riley.

Mattis, J., Jagers, R. J., Hatcher, C., Lawhon, D., Murphy, E, \& Murray, Y. (2000). Religiosity, volunteerism and community involvement among African American men. Journal of Community Psychology, 28(4), 391-406.

McLoyd, V.C. (2004). Linking race and ethnicity to culture: Steps along the road from inference to hypothesis testing. Human Development, 47, 185-191.

Moore, T. (2003). Promoting change through the African American church and social activism. Journal of Psychology and Christianity, 22(4), 357-362.

Myers, L.J., \& Haggins, K. L. (1998). Optimal theory and identity development: Beyond the cross model. In R.L. Jones (Ed.) African American Identity Development. Hampton, VA: Cobb \& Henry Publishers.

Myers, L. J. (1988). Understanding the Afrocentric worldview: Introduction to an optimal psychology. Dubuque, IA: Kendall/Hunt.

Nobles, W.W. (1998). To be African or not to be: The question of identity or authenticity-some preliminary thoughts. In R.L. Jones (Ed.) African American Identity Development. Hampton, VA: Cobb \& Henry Publishers.

Nobles, W.W. (1986). African psychology: towards its reclamation, reascension and 
revitalization. Oakland, California: Institute for the Advanced Study of Black Family Life and Culture, Inc. 18, 3-4

Olmeda, R.E. \& Kaufman, J.M. (2003). Sociocultural considerations in social skills training research with African American students with emotional or behavioral disorders. Journal of Developmental and Physical Disabilities,15(2), 101-121.

Oyserman, D., Harrison, K., \& Bybee, D. (2001). Can racial identity be promotive of academic efficacy? International Journal of Behavioral Development, 25(4), 379385.

Oyserman, D., Grant, L., \& Ager, J. (1995). A socially contextualized model of African American identity: Possible selves and school persistence. Journal of Personality and Social Psychology, 69(6), 1216-1232.

Parham, T.A., White, J.L, \& Ajamu, A. (1999). The Psychology of Blacks: An African Centered Perspective. Prentice Hall: New Jersey.

Pedhazur, E. J., and Schmelkin, L.P. (1991). Multiple Regression Analysis. In E.J. Pedhazur and L.P. Schmelkin (Eds.), Measurement, Design, and Analysis: An Integrated Approach. (pp. 413-463). Hillsdale, NJ: Lawrence Erlbaum Associates.

Phinney, J.S. (1990). Ethnic identity in adolescents and adults: Review of research. Psychological Bulletin, 108(3), 499-514.

Resnicow, K., Soler, R.E., Braithwaite, R.L., Ben Selassie, M., \& Smith, M. (1999). 
Development of a racial and ethnic identity scale for African American adolescents: The Survey of Black Life. Journal of Black Psychology, 25 (2), 171188.

Sanders-Thompson, V. L. (2001). The complexity of African American racial identity. Journal of Black Studies, 32 (2).

Scott Jr., L.D. (2003). Cultural orientation and coping with perceived discrimination among African American youth. Journal of Black Psychology, 29(3), 235-256.

Sellers, R. M., Shelton, J. N., Rowley, S., \& Chavous, T. M. (1998). A multidimensional model of racial identity: A re-conceptualization of African American racial identity. Personality and Social Psychology, 2(1), 18-39.

Sellers, R.M., Rowley, S.A.J., Chavous, T.M., Shelton, J.N., \& Smith, M.A. (1997). Multidimensional inventory of Black identity: Preliminary investigation of reliability and construct validity. Journal of Personality and Social Psychology, 73, 805-815.

Sellers, R.M., Shelton, J.N., Cooke, D.Y., Chavous, T.M., Johnson-Rowley, S.A., \& Smith, M.A. (1998). A multidimensional model of racial identity: Assumptions, findings, and future directions. In R.L. Jones (Ed.) African American Identity Development. Hampton, VA: Cobb \& Henry Publishers.

Smedly, A. \& Smedly, B.D. (2005). Race as biology is fiction, racism as a social problem is real: Anthropological and historical perspectives on the social construction of race. American Psychologist, 60(1), 16-26.

Spencer, M.B. Fegley, S.G., \& Harpalini, V. (2003). A theoretical and empirical 
examination of identity as coping: Linking coping resources to the self processes of African American youth. Applied Developmental Science, 7(3), 181-188.

Stevenson, H.C. (1998). Theoretical considerations in measuring racial identity and socialization: Extending the self further. In R.L. Jones (Ed.) African American Identity Development. Hampton, VA: Cobb \& Henry Publishers.

Stevenson, H.C. (1995). Relationship of adolescent perceptions of racial socialization to racial identity. Journal of Black Psychology, 21(1), 49-70.

Stevenson, H.C. (1994). Validation of the Scale of Racial Socialization for African American adolescents: Steps toward multidimensionality. Journal of Black Psychology, 20(4), 445-468.

Stevenson, H. C., Cameron, R., Herrero-Taylor, T., Davis, G. (2002). Development of the Teenager Experience of Racial Socialization Scale: Corelates of race-related socialization and frequency from the perspective of Black youth. Journal of Black Psychology, 28(2).

Stokes, J.E., Murray, C.B., Peacock, M.J., and Kaiser, R.T. (1994). Assessing the reliability, factor structure, and validity of the African Self-consciousness Scall in a general population of African Americans. Journal of Black Psychology, 20 (1), $62-74$.

Walsh, J.J. (2001). The Multidimensional Inventory of Black Identity: A validation study in a British sample. Journal of Black Psychology, 27(2), 172-189. 
Appendix A

\begin{tabular}{|c|c|}
\hline Cultural Orientation items & Racial Orientation items \\
\hline $\begin{array}{l}\text { 1. In my family it is expected that the elderly are cared for by the } \\
\text { younger generations. (Communalism) }\end{array}$ & $\begin{array}{l}\text { 1. Blacks should strive to be full members of the American } \\
\text { political system. (MIBI) }\end{array}$ \\
\hline $\begin{array}{l}\text { 2. It is family group membership which gives me a sense of } \\
\text { personal identity. (Communalism) }\end{array}$ & $\begin{array}{l}\text { 2. Blacks should try to work within the system to achieve } \\
\text { their political and economic goals. (MIBI) }\end{array}$ \\
\hline $\begin{array}{l}\text { 3. I don't believe that people should view themselves as separate } \\
\text { from friends and family. (Communalism) }\end{array}$ & $\begin{array}{l}\text { 3. Blacks should try to integrate all institutions that are } \\
\text { segregated. (MIBI) }\end{array}$ \\
\hline 4. I am always interested in listening to what my older relatives & 4. Blacks should feel free to interact socially with white \\
\hline have to say because I believe with age comes wisdom. & people. (MIBI) \\
\hline (Communalism) & 5. Blacks should have the choice to marry other races. (MIBI) \\
\hline 5. We all must depend on others for our existence and fulfillment. & 6. Blacks would be better off if the were more concerned with \\
\hline (Communalism) & the problems facing all people than just focusing on Black \\
\hline 6. It is important for Black people to surround their children with & issues. (MIBI) \\
\hline Black art, music and literature. (MIBI) & 7. The struggle for Black liberation in America should be \\
\hline
\end{tabular}


7. Blacks would be better off if they adopted Afrocentric values. $(M I B I)$

8. Teachers should make it so Black children can see signs of Black culture in the classroom. (Sors-A)

9. Spiritual battles that people fight are more important than the physical battles. (Sors-A)

10. Black parents should talk about their roots to African culture to their children. (Sors-A) closely related to the struggle of other oppressed groups.

$(M I B I)$

8. The racism Blacks have experienced is similar to that of other minority groups. (MIBI)

9. Black people must organize themselves into a separate

Black political force. (MIBI)

10. If Black parents teach their children that Blacks have fewer opportunities than Whites, it may help them survive racism and be successful. (Sors- $A$ ) 


\section{Appendix B}

Item ratings by graduate student colleagues

ITEMS

$\begin{array}{lll}\text { Rater } & \text { Rater } & \text { Rater } \\ \# 1 & \# 2 & \# 3\end{array}$

\begin{tabular}{|c|c|c|c|}
\hline \multicolumn{4}{|l|}{ (Communalism) } \\
\hline $\begin{array}{l}\text { 1. Although I might receive a lot of support from my close social relations, I don't think it is important that I give } \\
\text { a lot in return. }\end{array}$ & $\mathrm{C}$ & $\mathrm{C}$ & $\mathrm{N}$ \\
\hline 2. In my family it is expected that the elderly are cared for by the younger generations. & $\mathrm{C}$ & $\mathrm{C}$ & $\mathrm{C}$ \\
\hline 4. I believe that I can know myself better by getting to know my family and close friends. & $\mathrm{C}$ & $\mathrm{C}$ & $\mathrm{C}$ \\
\hline 5. I don't mind if my aunts and uncles come to live with me. & $\mathrm{C}$ & $\mathrm{C}$ & $\mathrm{C}$ \\
\hline $\begin{array}{l}\text { 6. For me, increasing the quality of the relationships with family and friends is one of the most productive ways to } \\
\text { spend time. }\end{array}$ & $\mathrm{C}$ & $\mathrm{C}$ & $\mathrm{C}$ \\
\hline 8. One big reason why people should own things is so that they can share with others. & $\mathrm{C}$ & $\mathrm{C}$ & $\mathrm{C}$ \\
\hline 9. In my family there are close friends which we consider family. & $\mathrm{C}$ & $\mathrm{C}$ & $\mathrm{C}$ \\
\hline 10. There are very few things I would not share with my family members. & $\mathrm{C}$ & $\mathrm{C}$ & $\mathrm{C}$ \\
\hline 11. I am happiest when I am part of a group. & $\mathrm{C}$ & $\mathrm{C}$ & $\mathrm{N}$ \\
\hline 12. It is family group membership which gives me a sense of personal identity. & $\mathrm{C}$ & $\mathrm{C}$ & $\mathrm{C}$ \\
\hline 13. Older members of my family are often relied on for advice/guidance. & $\mathrm{C}$ & $\mathrm{C}$ & $\mathrm{C}$ \\
\hline 18. I enjoy helping family members accomplish their goals. & $\mathrm{C}$ & $\mathrm{C}$ & $\mathrm{N}$ \\
\hline
\end{tabular}

$\mathrm{C}=$ Cultural Orientation, $\mathrm{R}=$ Racial Orientation, \& $\mathrm{N}=$ Neither 
19. I take care of my own needs before I consider the needs of others.

20. I don't believe that people should view themselves as separate from friends and family.

21. I am always interested in listening to what my older relatives have to say because I believe that with age comes wisdom.

22. I prefer to work in a group.

23. I am more concerned with personal gains than with those of my family and friends.

24. Among my family members, it is understood that we should turn to one another in time of crisis.

25. I place great value on social relations among people.

26. I make sacrifices for my family and they do the same for me.

27. My first responsibility is to myself rather than to my family.

28. I am constantly aware of my responsibility to my family and friends.

29. I believe that when people are "close" to one another (like family or friends) they should be accountable for each other's well-being.

30. I place high value on my duty to the group.

31. We all must depend on others for our existence and fulfillment.

(Multidimensional Inventory of Black Identity)

32. In general, being Black is an important part of my self-image

33. I feel good about Black people.

34. Blacks should strive to be full members of the American political system.

35. Blacks should have the choice to marry other races

36. The same forces which have led to the oppression of Blacks have also led to the oppression of other groups.

37. It is important for Black people to surround their children with Black art, music and literature.

38. I have a strong sense of belonging to Black people.

39. I am happy that I am Black.

40. Blacks should try to work within the system to achieve their political and economic goals.

41. Blacks would be better off if they were more concerned with the problems facing all people than just focusing on Black issues.

42. The struggle for Black liberation in America should be closely related to the struggle of other oppressed groups.

43. Blacks would be better off if they adopted Afrocentric values.

\begin{tabular}{|c|c|c|}
\hline $\mathrm{C}$ & $\mathrm{C}$ & $\mathrm{N}$ \\
\hline $\mathrm{C}$ & $\mathrm{C}$ & C \\
\hline C & C & C \\
\hline $\mathrm{N}$ & C & $\mathrm{N}$ \\
\hline $\mathrm{C}$ & $\mathrm{C}$ & $\mathrm{N}$ \\
\hline $\mathrm{C}$ & $\mathrm{C}$ & $\mathrm{C}$ \\
\hline C & $\mathrm{C}$ & $\mathrm{N}$ \\
\hline $\mathrm{C}$ & $\mathrm{C}$ & C \\
\hline C & $\mathrm{C}$ & $\mathrm{C}$ \\
\hline $\mathrm{C}$ & $\mathrm{C}$ & $\mathrm{C}$ \\
\hline C & $\mathrm{C}$ & $\mathrm{C}$ \\
\hline C & C & C \\
\hline $\mathrm{C}$ & $\mathrm{C}$ & $\mathrm{C}$ \\
\hline $\mathrm{R}$ & $\mathrm{C}$ & $\mathrm{N}$ \\
\hline $\mathrm{R}$ & $\mathrm{C}$ & $\mathrm{N}$ \\
\hline $\mathrm{R}$ & $\mathrm{R}$ & $\mathrm{R}$ \\
\hline $\mathrm{R}$ & $\mathrm{R}$ & $\mathrm{R}$ \\
\hline $\mathrm{R}$ & $\mathrm{R}$ & $\mathrm{R}$ \\
\hline $\mathrm{C}$ & $\mathrm{C}$ & $\mathrm{C}$ \\
\hline $\mathrm{R}$ & $\mathrm{C}$ & $\mathrm{N}$ \\
\hline C & $\mathrm{C}$ & $\mathrm{N}$ \\
\hline $\mathrm{R}$ & $\mathrm{R}$ & $\mathrm{R}$ \\
\hline $\mathrm{R}$ & $\mathrm{R}$ & $\mathrm{R}$ \\
\hline $\mathrm{R}$ & $\mathrm{R}$ & $\mathrm{R}$ \\
\hline $\mathrm{N}$ & C & C \\
\hline
\end{tabular}




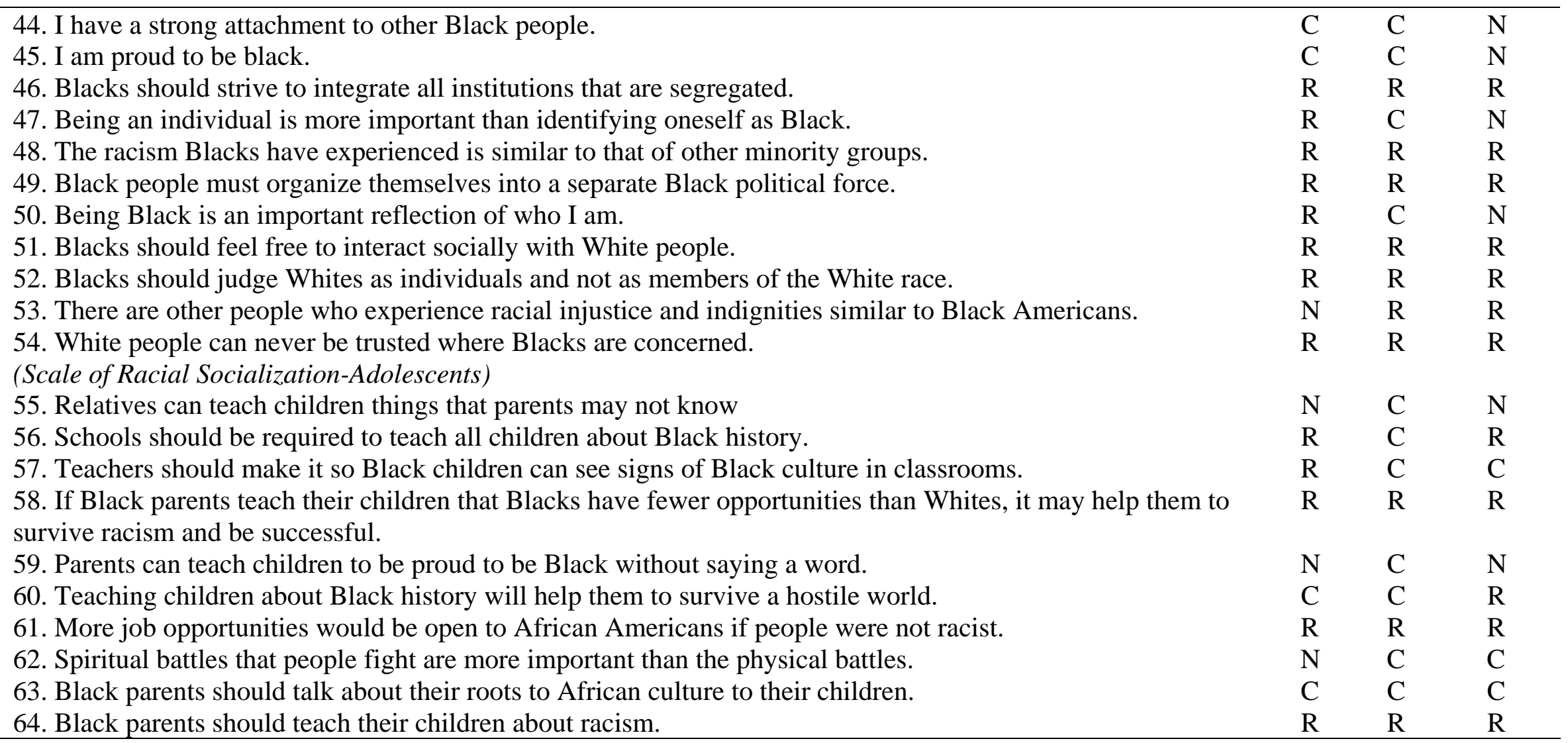

$\mathrm{C}=$ Cultural Orientation, $\mathrm{R}=$ Racial Orientation, \& N=Neither 
Appendix C: Zero Order Correlations Matrix for all Study Variables

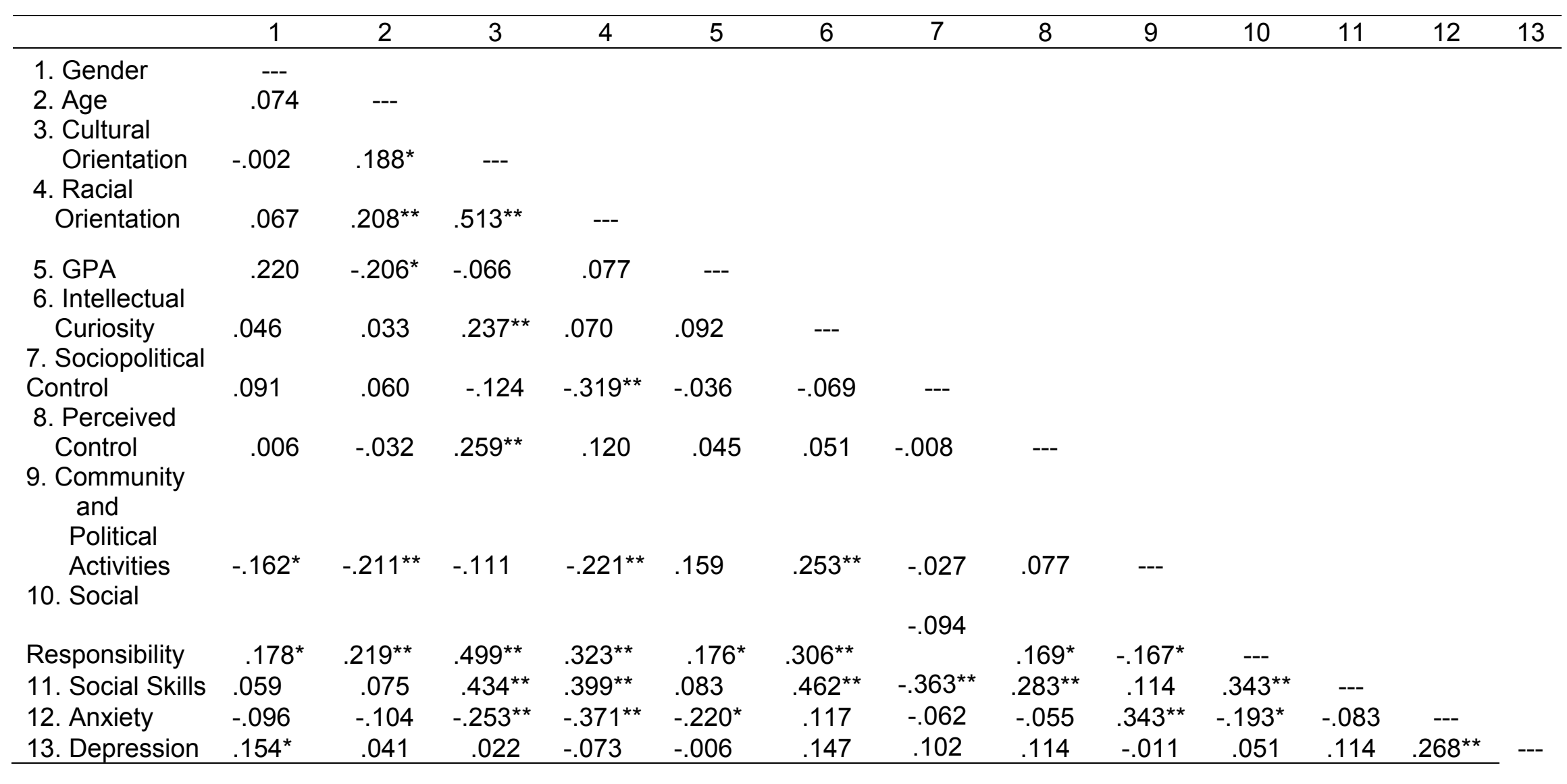

${ }^{* *} p \leq .01 .{ }^{*} p \leq .05$ 